\title{
THE ROLE OF FOLLISTATIN AND GRANULOCYTE-COLONY STIMULATING FACTOR
}

IN

\section{HIV-ASSOCIATED PRE-ECLAMPSIA}

By

SIPHESIHLE MDLALOSE

Submitted in partial fulfilment for the degree of

\section{MASTER OF MEDICAL SCIENCE}

in the

\author{
Discipline of Optics and Imaging \\ Doris Duke Medical Research Institute \\ College of Health Sciences \\ University of KwaZulu-Natal \\ Durban, South Africa
}

2018 


\section{PREFACE}

This study represents original work by the author and has not been submitted in any other form to another University. Where use was made of the work of others, it has been duly acknowledged in the text.

The research described in this dissertation was carried out in the Optics \& Imaging Centre, Doris Duke Medical Research Institute, College of Health Sciences, University of KwaZulu-Natal, Durban, South Africa under the supervision of Professor T. Naicker

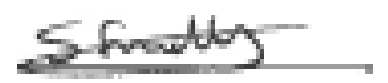

Siphesihle Mdlalose

Professor Thajasvarie Naicker

(Student number: 217011521)

(Supervisor) 


\section{DECLARATION}

I, Siphesihle Mdlalose declare that:

i. The research reported in this dissertation, except where otherwise indicated is my original work.

ii. This dissertation has not been submitted for any degree or examination at any other university.

iii. This dissertation does not contain other person's data, pictures, graphs or other information, unless specifically acknowledged as being sourced from other persons.

iv. This dissertation does not contain other persons writing, unless specifically acknowledged as being sourced from other researchers. Where other sources have been quoted, then:

a. Their words have been rewritten but the general information attributed by them has been referenced.

b. Where their exact words have been used their writing has been placed inside quotation marks and referenced.

v. Where I have reproduced a publication of which I am the author, co-author, I have indicated in detail which part of the publication was actually written by myself alone and have fully referenced such publications.

vi. This dissertation does not contain text, graphics, or tables copied and pasted from the internet, unless specifically acknowledged and the source being detailed in the dissertation and the reference sections.

Signed:

Date: 


\section{ORAL PRESENTATION}

- Mdlalose S, Moodley J and Naicker T (2018). Investigating the angiogenic role of follistatin in HIV-associated pre-eclampsia. Pre-eclampsia Awareness in week KZN (2018).

\section{POSTER PRESENTATION}

- Mdlalose S, Moodley J and Naicker T (2018). The role of follistatin in HIV-associated preeclampsia. College of Health Science Research Symposium (UKZN), October 2018.

- Mdlalose S, Moodley J and Naicker T (2018). The role of follistatin in HIV-associated preeclampsia. The fourth $\mathrm{x}$-Map connect sharing multiplex solutions meeting (Amsterdam, Netherlands), November 2018.

-Mdlalose S, Moodley J and Naicker T (2018). The role of follistatin in HIV-associated preeclampsia. The $2^{\text {nd }}$ International Meeting on Gynaecology and Obstetrics Pathology (Paris, France), November 2018. 


\section{DEDICATIONS}

To God-To the alpha and omega. I have stayed strong in faith and prayed throughout the completion of my thesis. I know you have been watching me and helped me through this beautiful journey.

My parents- the emotional and financial support you both have given me is what any child would want. I love you!!

My family and friends-I appreciate the encouragement and the constant question, "when are you submitting?" This question has kept me on the right path and motivated me to work hard. 


\section{FUNDING}

This research study was funded by:

1. The publication fund of Professor T. Naicker, University of KwaZulu-Natal.

2. The National Research Fund Foundation. 


\section{ACKNOWLEDGEMENTS}

\section{I wish to express my sincere thanks and gratitude to:}

- Professor T. Naicker my supervisor, as her extensive up-to date knowledge on science has been of irreplaceable value and for her support, encouragement and her invaluable supervision with regards to this thesis.

- Professor J. Moodley for the most professional and careful review of my work.

- Optics and Imaging Centre, DDMRI, College of Health Sciences, where this study was conducted.

- Ms. Fikile Nkwanyana for her assistance with the statistical analysis.

- Dr. P. D Shallie and Dr. O. M Alese for their assistance and guidance.

- My parents, who have provided me with unconditional love and support.

- My sisters, Sibusisiwe and Lethokuhle for their love, encouragement and support.

- My friends and colleagues are warmly acknowledged for their positive attitude and support. 


\section{TABLE OF CONTENTS}

PREFACE.

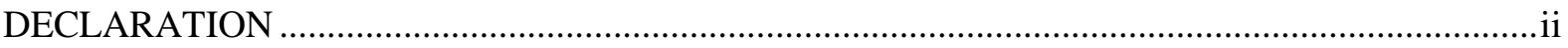

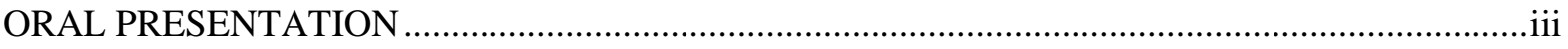

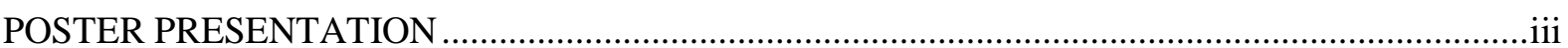

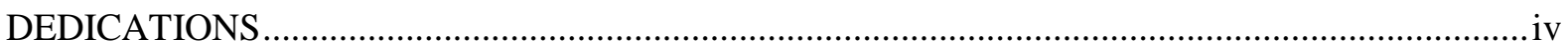

FUNDING …

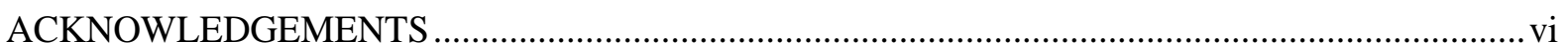

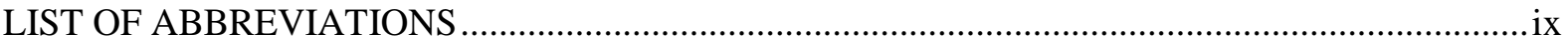

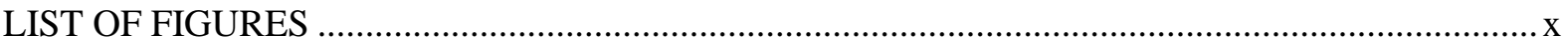

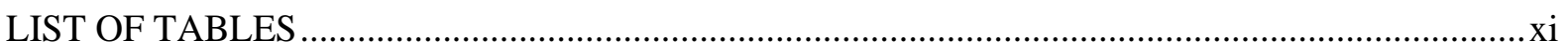

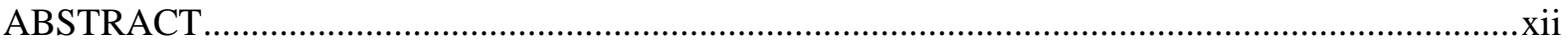

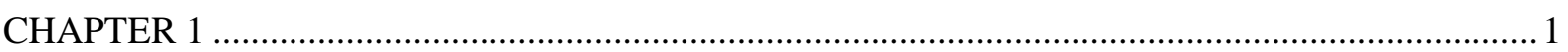

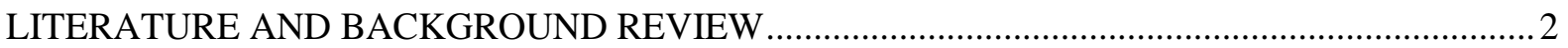

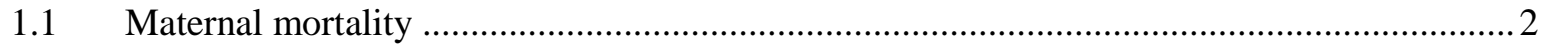

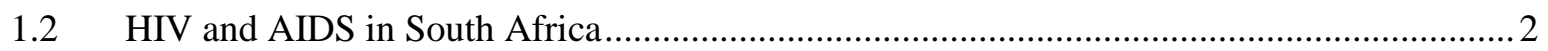

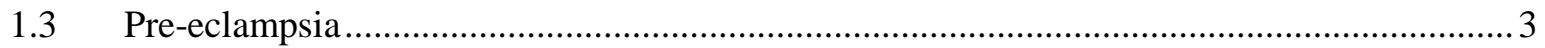

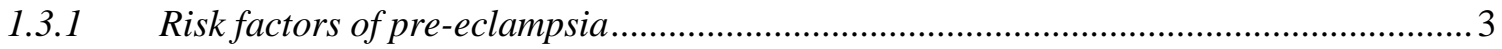

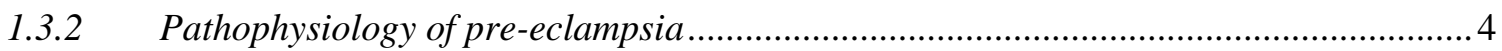

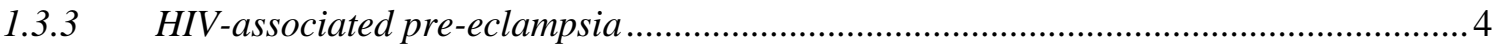

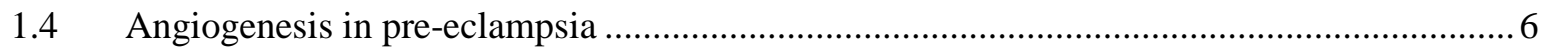

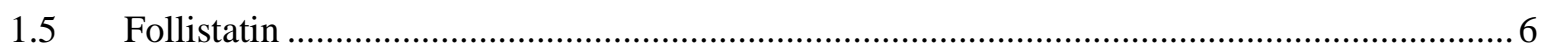

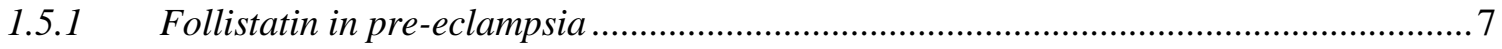

1.5.2 Follistatin in HIV-associated pre-eclampsia ............................................................ 8

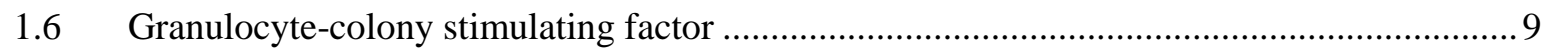

1.6.1 Granulocyte-colony stimulating factor in pre-eclampsia ............................................. 9

1.6.2 Granulocyte-colony stimulating factor in HIV-associated pre-eclampsia..................... 10

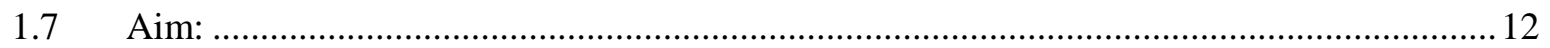

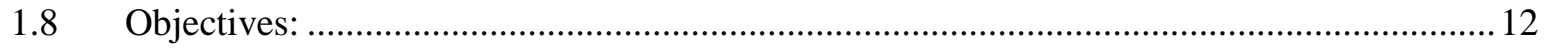




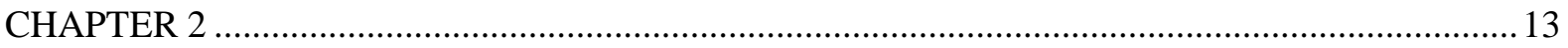

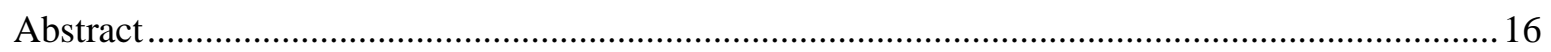

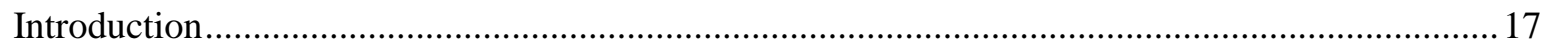

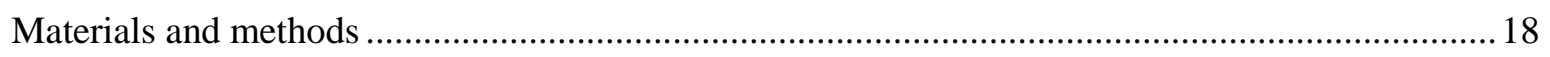

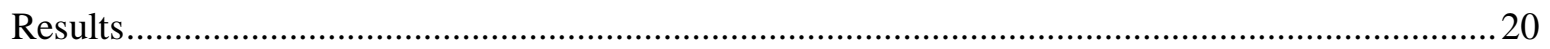

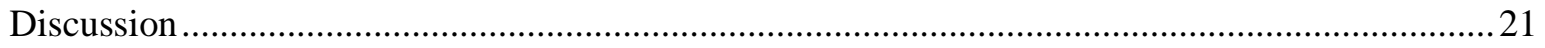

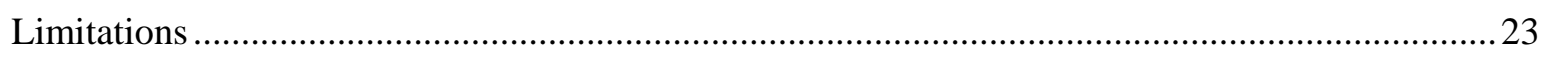

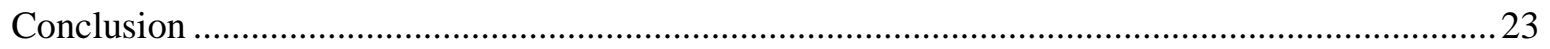

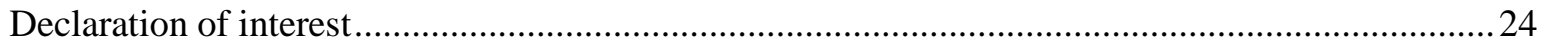

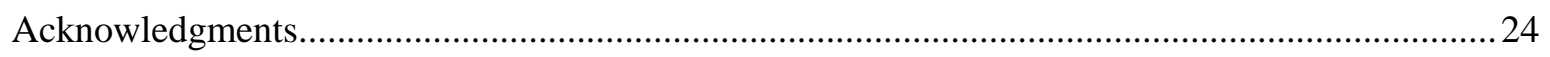

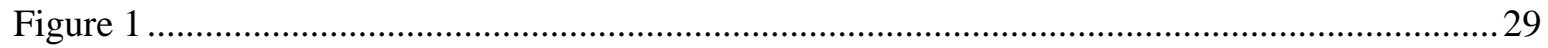

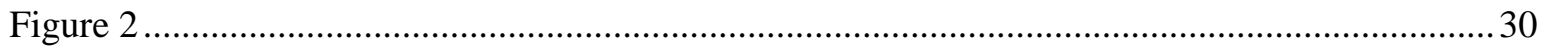

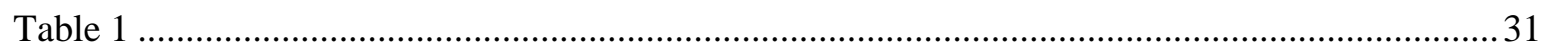

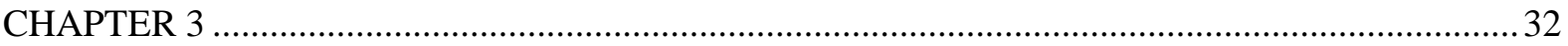

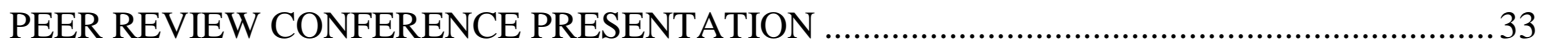

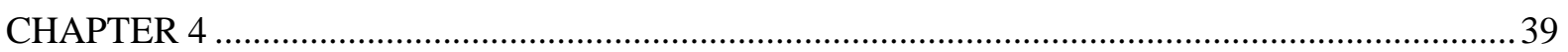

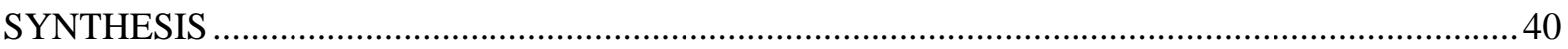

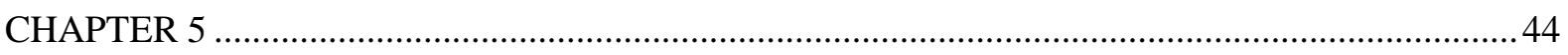

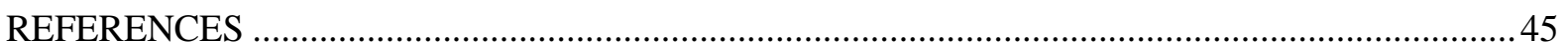

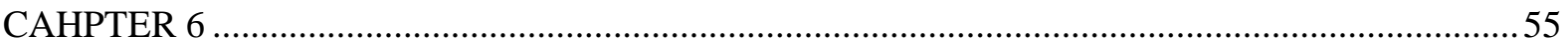

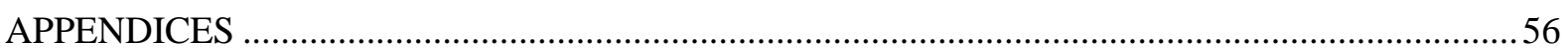

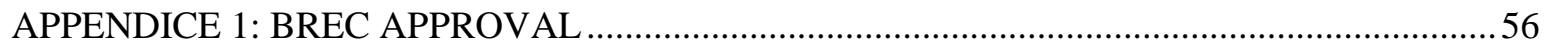

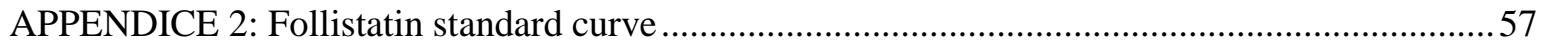

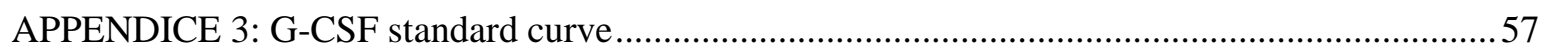




\section{LIST OF ABBREVIATIONS}

$+\mathrm{ve}$

AIDS

ART

CD4

FS.

FSH

FSL3.

G-CSF.

HAART.

HIV

IFN.

IL

LPS

MAPK

MFI.

NOX 2

PE.

PIGF.

ROS

SA.

SA-PE.

sEng

sFlt1

TGF- $\beta 1$

TNF.

-ve.

VEGF

vs.

WHO
Positive

Acquired immunodeficiency virus

Antiretroviral therapy

Cluster of differentiation

Follistatin

Follicle stimulating hormone

Follistatin-like 3

Granulocyte-colony stimulating factor

Highly active antiretroviral therapy

Human immunodeficiency virus

Interferon

Interleukin

Lipopolysaccharides

Mitogen-activated protein kinase

Median fluorescent intensity

NADPH Oxidase 2

Pre-eclampsia

Placental growth factor

Reactive oxygen species

South Africa

Streptavidinphycoerythrin

Soluble endoglin

Soluble fms-like tyrosine kinase-1

Transforming growth factor- $\beta 1$

Tumour necrosis factor

Negative

Vascular endothelial growth factor

Versus

World health organization 


\section{LIST OF FIGURES}

Figure legend

\section{Chapter 1}

Figure 1.1: $\quad$ A complex model showing the pathophysiology of pre-eclampsia

Figure 1.2:

The regulation of activin signalling by follistatin

Figure 1.3:

The basic cellular activities of Granulocyte-colony stimulating factor

\section{Chapter 2}

Figure 1:

FS expression: (1A) based on HIV status (1B) based on pregnancy type (1C) across all study groups

Figure 2:
G-CSF expression: (2A) based on HIV status (2B) based on pregnancy type (1C) across all study groups
29

Page No.

5

7

11

30 


\section{LIST OF TABLES}

TABLE LEGEND

Chapter 2

Table 1
PAGE NO.

31 


\begin{abstract}
Introduction: KwaZulu-Natal has a high burden of HIV infection and high blood pressure, specifically pre-eclampsia (PE) in pregnancy. Follistatin (FS) and granulocyte-colony stimulating factor (G-CSF) are two glycoproteins involved in PE pathogenesis. FS is an extracellular glycoprotein antagonist of the ligand receptor, activin. G-CSF on the other hand drives the generation of neutrophilic granulocytes from myeloic precursor cells by its inhibition of apoptosis and induction of differentiation. In light of the high maternal mortality and morbidity in South Africa (SA), we investigated the expression of FS and G-CSF in the duality of HIV-associated PE.

Method: Serum samples of normotensive and pre-eclamptic women further stratified by HIV status were collected from a large regional hospital in Durban, and their FS and G-CSF expression was analysed using the Bio-Plex Multiplex Immunoassay.

Results: FS expression was significantly reduced in pre-eclamptic compared to normotensive pregnancies $(649.5 \pm 116.8$ vs $2354 \pm 353.6$; $p<0.001)$. However, FS expression did not differ between HIV +ve $v s$ HIV -ve groups (1727 \pm 291.2 vs $1305 \pm 306.7 ; p=0.13)$. Furthermore, we detected significant FS expression across all study groups. The expression of G-CSF was not affected by HIV status i.e., between HIV +ve $v s$ HIV -ve groups $(14.4 \pm 2.3$ vs $11.6 \pm 0.7, p=0.10)$ and there was no significant difference in the expression of G-CSF between normotensive $v s$ pre-eclamptic (14.9 2.4 vs $11.3 \pm 0.5$, $p=0.32$ ). G-CSF expression was notably higher in HIV +ve normotensive when compared to all study groups.

Conclusion: This study demonstrates a downregulation of FS and G-CSF expression in PE, compared to normotensive pregnancies. This finding may be attributed to oxidative stress and its immunoregulatory role in the hyper-inflammatory milieu of PE. In addition, the downregulation of both analytes may be attributed to the anti-angiogenic micro-environment of PE. HIV status probably had no effect on both analytes albeit, upregulated due to immune reconstitution emanating from HAART. Our novel findings suggest that FS and G-CSF may have a potential predictor test value in early pregnancy, hence work on this is ongoing.
\end{abstract}




\section{CHAPTER 1}




\section{LITERATURE AND BACKGROUND REVIEW}

\subsection{Maternal mortality}

Maternal mortality is the death of a woman during pregnancy, childbirth or within the 42 days after delivery (Hogan et al., 2010). The Safe Motherhood Initiative was introduced in 1987 as a global initiative to raise awareness of the lack of health programmes concerning maternal health in developing countries (Hogan et al., 2010). The World Health Organization (WHO) reports that 830 women die globally due to pregnancy related complications every day, of these deaths $99 \%$ of them occur in developing countries (WHO, 2018).

Maternal mortality is high amongst women living in sub-Saharan Africa, where $56 \%$ of people living with HIV are women (UNAIDS, 2018). Notably, pregnancy related complications in South Africa (SA) are a major public health issue (Moodley et al., 2018). Pregnancy places all women at risk for a pregnancy-related event however, some women are at a higher risk of morbidity and mortality (Hirshberg and Srinivas, 2017). The main cause of maternal deaths in SA result from non-pregnancy related infections such as HIV infection, tuberculosis and pneumonia. Reliable data from SA emanating from WHO recommendations for the Safe Motherhood programme underscores HIV/AIDS as the most common cause of maternal deaths (Moodley et al., 2010). The remaining causes of maternal deaths are haemorrhage, high blood pressure, unsafe abortions and complications from delivery (Say et al., 2014). Additionally, hypertensive disorders are the most common medical complication in pregnancy and account for $20.7 \%$ of maternal deaths within SA (Saving mothers 2014-2016, 2017).

\subsection{HIV and AIDS in South Africa}

HIV infection compromises an individual's immune system by causing a progressive loss of CD4+ T cells (Poulton, 2018). Globally more than 2 million HIV infected women become pregnant every year, with the majority residing in sub-Saharan Africa (Moodley et al., 2010). SA has a high HIV infection prevalence with an estimated number of 7.52 million infected in 2018 (Statistics, 2018). Approximately one-fifth of women from SA in their reproductive ages (15-49 years) are HIV +ve, increasing the risk of mother to child HIV transmission (Dellar et al., 2015;Statistics, 2018). This form of HIV transmission occurs at 3 stages:

1) During pregnancy when HIV crosses the placenta. 
2) During delivery through the contact of vaginal secretions or blood.

3) During breast-feeding via breastmilk (Poulton, 2018).

\subsection{Pre-eclampsia}

Hypertension is defined as the presence of a chronic elevation of systemic arterial pressure above a certain threshold (Khaliq et al., 2018). The number individuals affected by hypertension is expected to increase by approximately 560 million people worldwide by the year 2025 (Poulter et al., 2015). Hypertensive disorders are responsible for a large amount of pregnancy complications in developing countries, such as SA (Hutcheon et al., 2011). There are various types of hypertensive disorders however, this study will be looking at pre-eclampsia (PE).

$\mathrm{PE}$ is a systemic syndrome identified by proteinuria, new-onset hypertension and poor placental perfusion in pregnant women (Hutcheon et al., 2011). Maternal mortalities as a result of PE are estimated at 15-20\% in developing countries (Sibai et al., 2005). The risk of a mother dying due to $\mathrm{PE}$ are higher in regions such as sub-Saharan Africa in comparison to developed countries (Abalos et al., 2013). In SA, PE accounts for $14.8 \%$ of all maternal deaths (Saving mothers 20142016, 2017). The diagnostic criteria for PE remains contentious, with angiogenic biomarkers remaining a predictor test for the development of PE (Sibai et al., 2005).

\subsubsection{Risk factors of pre-eclampsia}

Pre-eclampsia has various risk factors, in fact it is considered "the disease of theories" as its pathogenesis is varied, not concise and unclear (Trogstad et al., 2011). Women who are at high risk of developing PE include those with pre-existing hypertension, chronic kidney disease and women with previous early onset PE (English et al., 2015). Additional risk factors include smoking in pregnancy, multiple gestations and also ethnicity; Black women are at a higher risk when compared to White women (Trogstad et al., 2011). There are familial factors that contribute to PE development, where a family history of PE increases the risk of PE development (Hutcheon et al., 2011). Moreover, numerous evidence shows that paternal genes significantly increase the risk of PE (Agius et al., 2018). 


\subsubsection{Pathophysiology of pre-eclampsia}

For the successful implantation of the placenta, complex interactions occur. Placentation involves trophoblast invasion of maternal spiral arteries by trophoblast cells (Gathiram and Moodley, 2016). The invasion of trophoblasts cells via the decidua results in the transformation of spiral arteries into low-resistance vessels (Trogstad et al., 2011). These trophoblast cells are also responsible for cytokine production, communication of maternal immune cells and angiogenesis (Trogstad et al., 2011). A pregnant woman reacts to the foetal trophoblast through a sterile, lowgrade maternal inflammatory response (Ngene and Moodley, 2017).

In pre-eclamptic women, trophoblast invasion is dysregulated and transformation of the myometrial spiral arteries is limited to the decidua during the first trimester of pregnancy (Figure 1.1) (Trogstad et al., 2011;Salman et al., 2018). The consequence of this is reduced blood flow to the placenta leading to poor fetal growth as a result of placental dysfunction (Gathiram and Moodley, 2016). The reduced blood flow results in an ishaemic placenta, which is identified as the central hypothesis governing pre-eclamptic pathogenesis (Chaiworapongsa et al., 2014). The ischaemic placenta releases pro-inflammatory factors into maternal circulation and causes systemic endothelial dysfunction leading to the clinical manifestations of the disease (Chaiworapongsa et al., 2014). The hypoxic micro-environment results in an excess generation of reactive oxygen species (ROS) (Trogstad et al., 2011). The accumulation of ROS causes a self perpetuating inflammatory response which results in chemical destruction and ultimately tissue degradation and cell death (Ngene and Moodley, 2017). The latter contributes to a physiological imbalance causing an exaggerated systemic inflammatory response (Pinheiro et al., 2013).

\subsubsection{HIV-associated pre-eclampsia}

South Africa has one of the largest public anti-retroviral therapy (ART) programmes in the world (Malaza et al., 2012). The introduction of highly active antiretroviral therapy (HAART) has resulted in an increase in the incidence of PE (Suy et al., 2006). However, HIV is responsible for the immune suppression of an infected women and PE is associated with an elevated immune response; hence a neutralization is expected. However, HAART reconstitutes ones immune response, thus increasing PE development (Phoswa et al., 2018). Nonetheless, the relationship between HIV infection, HAART and PE needs to be further investigated because of the high maternal mortality rate in SA. 


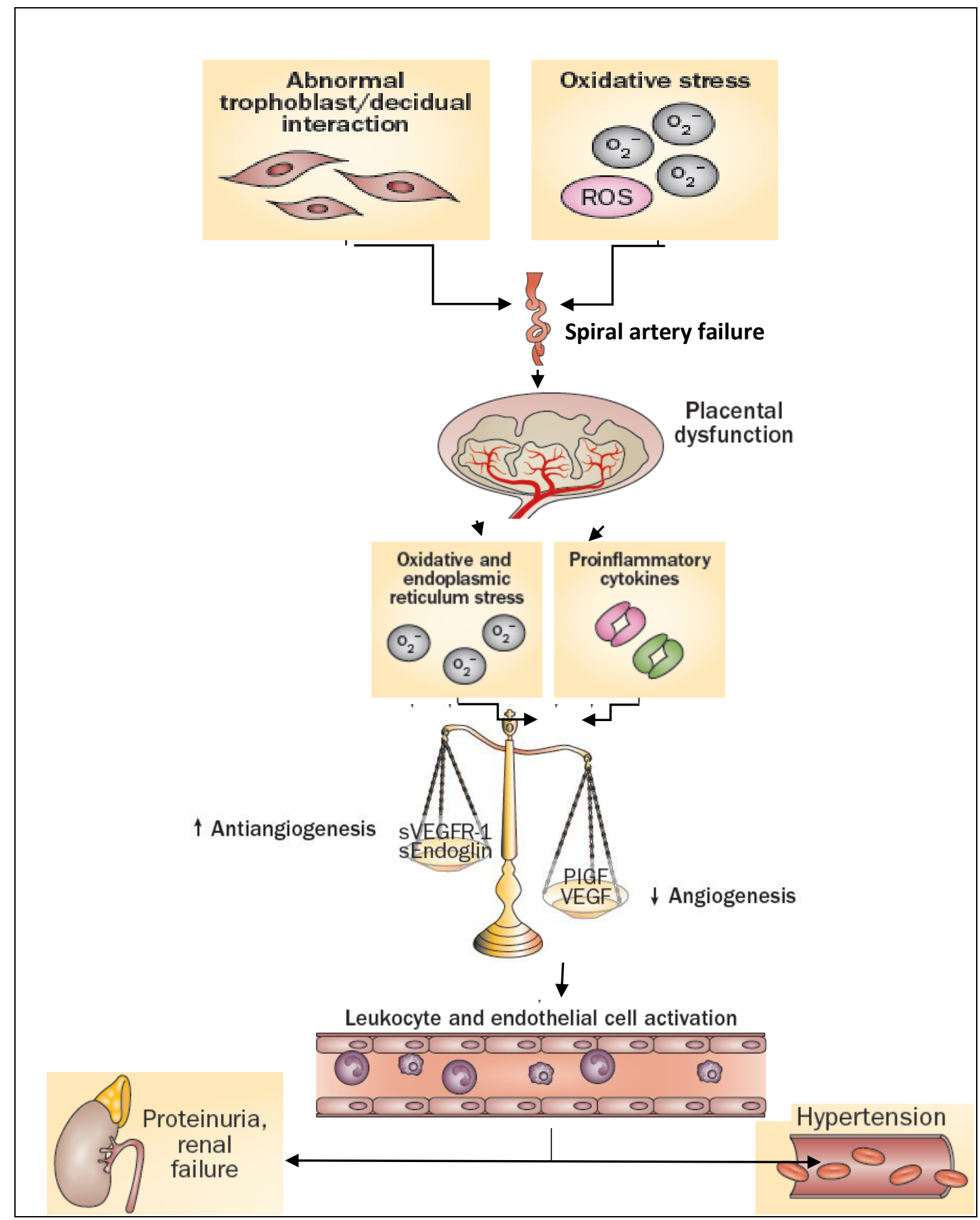

Figure 1.1: A complex model showing the pathophysiology of PE. In pre-eclamptic women there is dysregulation of trophoblast cells invasion, accompanied with oxidative stress. This results in the lack of myometrial spiral artery remodelling causing placental dysfunction. The ischaemic placenta releases ROS. Moreover, an angiogenic imbalance coupled with ROS results in endothelial dysfunction. Leukocyte and endothelial cell activation lead to the maternal clinical manifestations of the disease. Adapted from Chaiworapongsa et al. (2014). 


\subsection{Angiogenesis in pre-eclampsia}

Circulating anti-angiogenic proteins such as soluble fms-like tyrosine kinase-1 (sFlt1) and soluble endoglin (sEng) inhibit pro-angiogenic factors [vascular endothelial growth factor (VEGF) and placental growth factor (PIGF)] in PE (Karumanchi, 2016). VEGF plays a role in stabilizing endothelial cells in mature blood vessels and also maintains the endothelium in the kidney, brain and liver; organs severely affected in PE (Wang et al., 2009). PIGF stimulates angiogenesis under conditions of ischaemia, inflammation and wound healing (Wang et al., 2009). Literature shows that VEGF and transforming growth factor (TGF- $\beta 1$ ) play an essential role in maintaining the endothelium of the placenta (Karumanchi, 2016). In a normal pregnancy there is vascular homeostasis between angiogenic factors, VEGF and TGF- $\beta 1$ (Gathiram and Moodley, 2016). However, in PE excess placental excretion of endogenous anti-angiogenic proteins, sFlt1 and sEng inhibit VEGF and TGF- $\beta 1$ signalling in the vasculature causing endothelial cell dysfunction (Khaliq et al., 2018). The pathogenesis of PE involves the presence of an anti-angiogenic state, whereby the imbalance of angiogenesis is identified as the most important factor (Chaiworapongsa et al., 2014). There have been other proteins with angiogenic activity that have been implicated in PE development however, none have been established to have a predictor test value early in pregnancy (Maynard and Karumanchi, 2011).

\subsection{Follistatin}

Follistatin (FS) is an extracellular glycoprotein identified as an inhibitor of pituitary follicular stimulating hormone (FSH) secretion. It was first isolated from porcine follicular fluid (Hansen and Plomgaard, 2016). The FS protein functions by preventing the ligand-receptor interaction of activin, which belongs to the TGF- $\beta$ superfamily (Flanagan et al., 2009). The extracellular FS molecule binds to the activin homodimer with a high affinity, resulting in the restriction of activin bioavailability for the stimulation of FSH secretion (Keutmann et al., 2004). Additionally, FS is an important mediator of cell secretion, development and differentiation in numerous body systems (Sidis et al., 2001). Furthermore, it can be found in the pituitary, reproductive organs and also in the kidney (Blumenfeld and Ritter, 2001).

The distribution of FS occurs among all tissues in which activin is also present (Sidis et al., 2001). TGF- $\beta$ family members, including activin and myostatin bind to type I and type II receptors and 
lead to type I receptor phosphorylation (Zhang et al., 2018). This receptor then phosphorylates the secondary messenger molecule smads, which complexes with a common smad4 (Zhang et al., 2018). This complex then translocates to the nucleus where it activates gene transcription (Zhang et al., 2018). However, in the presence of extracellular FS, the TGF- $\beta$ superfamily members effects are neutralized as a result of FS binding to them (Figure 1.2) (Zhang et al., 2018).

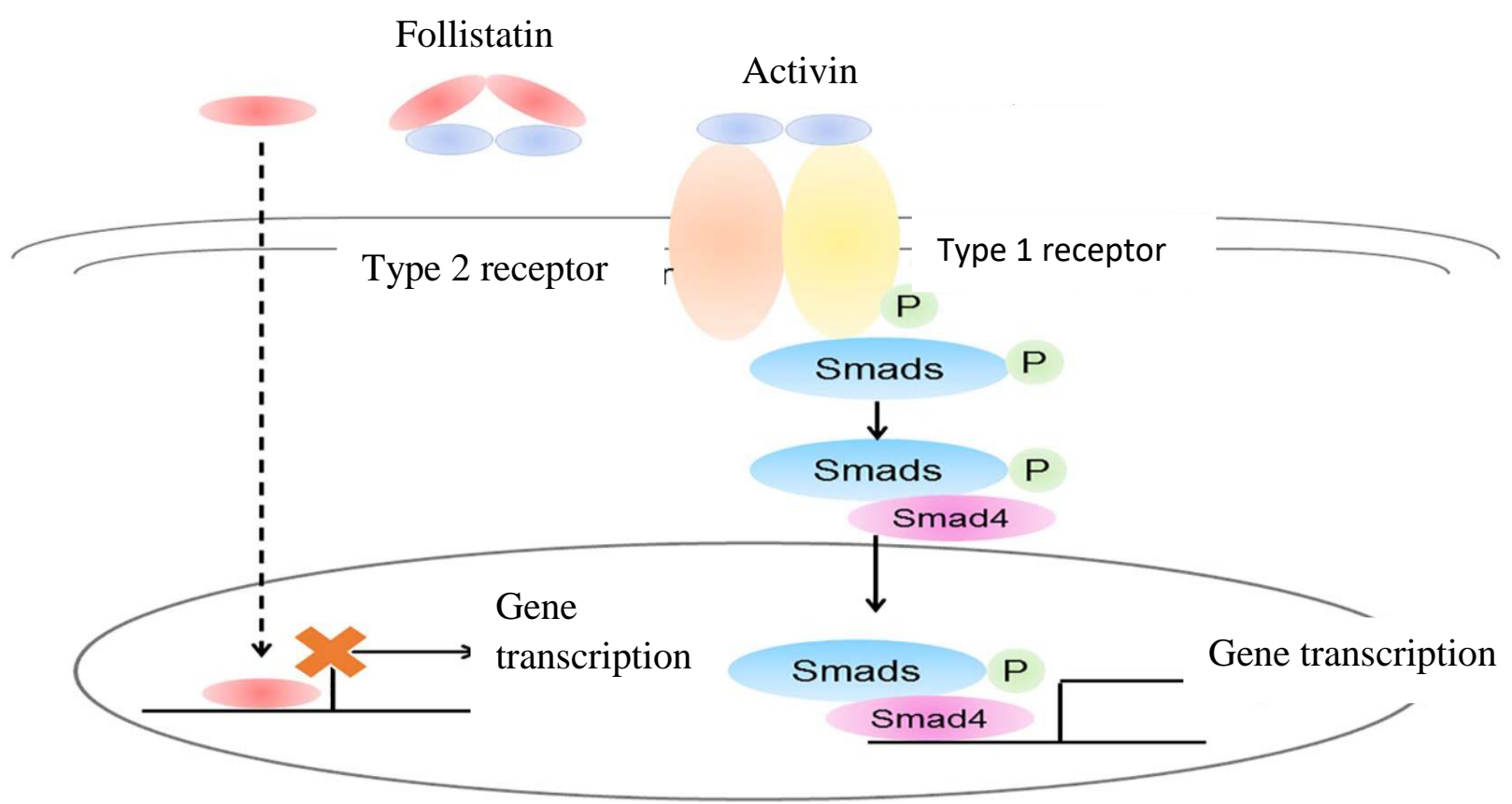

Figure 1.2: Diagram showing the regulation of activin signalling by follistatin. Two FS molecules, which bind activin thereby preventing binding of activin to its receptors. This inhibits gene transcription. Adapted from Zhang et al. (2018).

\subsubsection{Follistatin in pre-eclampsia}

Pre-eclamptic symptoms are a result of the ischaemic placenta and studies conducted on FS show that it has a role in regeneration after ischaemic injury (Welt et al., 2002). A rat model with arterial damage showed a reduction in histological defects after the infusion of FS, implicating FS in repair processes (Welt et al., 2002). Moreover, circulating levels of FS are not affected by a woman's reproductive tissues, so FS levels in the serum do not change during a woman's menstrual cycle (Hansen and Plomgaard, 2016). Studies show that the serum concentration of FS in small for gestational age infants is higher than in appropriate for gestational age infants (Sebastiani et al., 2011). This may be attributed to the role of FS in regulating fat, lean mass and muscle growth through its inhibitory effects on activin and myostatin (Anastasilakis et al., 
2016).The increase in FS levels could be a compensatory mechanism to regulate the infants' weight. Since we know that PE is associated with a baby's weight we can assume that FS serum levels will be elevated in PE. However, due to oxidative stress occurring in PE there will be a decrease in the levels of FS (Zhang et al., 2018). Previous studies conducted on FS have reported that in PE, FS functions in the inhibition of PE development via its pro-angiogenic role (Zhang et al., 2018).

\subsubsection{Follistatin in HIV-associated pre-eclampsia}

The FS protein is an important regulator of regulatory $\mathrm{T}$ cells, natural killer cells and also dendritic cells (Werner and Alzheimer, 2006). An HIV infected woman will have a depletion of CD4+ T cells resulting in an impaired cellular immune response (Okoye and Picker, 2013). Activin acts as a pro-inflammatory agent in diseases such as PE (Refaat et al., 2014). FS on the other hand plays a role in the inflammatory response by direct inhibition of activin (Miyamoto et al., 2011). Additionally, FS plays a role in both innate and humoral immune responses, with evidence implicating the protein in immune response to several pathogens including viruses (Werner and Alzheimer, 2006).

Since PE is associated with inflammation, there will be an upregulation of FS during inflammation (Hedger et al., 2011). This serves to counteract the effect of activin, which acts as a critical amplifier of inflammation (Hedger et al., 2011). Additional inflammatory cytokines such as IL1$\beta$, TNF- $\alpha$ and IFN- $\gamma$, also result in the upregulation of FS to mediate an inflammatory response (Hedger et al., 2011). Moreover, activin inhibits endothelial cell proliferation however, FS blocks this inhibitory effect because it is strongly expressed by migrating endothelial cells (Gerritsen, 2008). Literature suggests that FS may be a potential angiogenic biomarker that can counteract the development of PE however, it is unclear how FS expression is affected by HIV status in preeclamptic women. 


\subsection{Granulocyte-colony stimulating factor}

Granulocyte-colony stimulating factor (G-CSF) is a $19.6 \mathrm{kDa}$ glycoprotein consisting of 4 antiparallel $\alpha$ helicases. Originally identified in serum as it induced differentiation of the murine myelomonocytic leukemic cell line (Schneider et al., 2006). G-CSF is central in the production of neutrophils in healthy and diseased states in response to infection (Bendall and Bradstock, 2014). The prominent source of G-CSF is monocytes but fibroblasts, mesothelial and endothelial cells have been found to also produce G-CSF (Schneider et al., 2006). Various tissues can produce G-CSF when stimulated by inflammatory mediators such as lipopolysaccharides (LPS), TNF- $\alpha$, VEGF, macrophages and fibroblasts leading to an immune response (Cai et al., 2017).

In the hematopoietic system, G-CSF drives the generation of neutrophilic granulocytes from myeloic precursor cells by its inhibition of apoptosis and induction of differentiation (Figure 1.3) (Schneider et al., 2006). G-CSF serves as a growth factor that promotes the proliferation and differentiation of neutrophil progenitors (Basu et al., 2002). Additionally, G-CSF released in the blood stream stimulates the mobilization and production of neutrophils within the bone marrow (Bendall and Bradstock, 2014). When an infection occurs there is a typical host response to the infection, such as increased production of neutrophils (Basu et al., 2002). The locally produced G-CSF by tissues, mediates the function of these neutrophils at the infection site (Bendall and Bradstock, 2014).

\subsubsection{Granulocyte-colony stimulating factor in pre-eclampsia}

Studies have shown that the administration of G-CSF to healthy individuals or experimental animals result in an upregulation of neutrophil levels, 10 to 15 fold greater than normal levels (Basu et al., 2002). Neutrophils are responsible for the production of inflammatory cytokines such as IL-8 (Pinheiro et al., 2013). These neutrophils infiltrate the vasculature of women with PE and provide a chemotactic gradient that attracts more neutrophils (Pinheiro et al., 2013). The neutrophils will subsequently infiltrate into the intimal space where they release ROS consequently resulting in inflammation (Pinheiro et al., 2013). Endothelial cells monocytes and endometrial cells produce G-CSF, which plays an important role in trophoblastic development and placental metabolism (Kamath et al., 2017). There is a paucity of information on G-CSF serum levels in PE. However a study done by Natori et al. (2002) showed that G-CSF played a role in promoting angiogenesis in an animal model. There is evidence showing G-CSF has a direct 
stimulatory action on mature endothelial cells, thereby promoting angiogenesis. A study conducted by Lee et al. (2005) showed G-CSF directly stimulates endothelial cell migration and enhancing angiogenesis-like network formation on Matrix gel culture in vitro. This suggests that G-CSF will have a pro-angiogenic effect in PE.

\subsubsection{Granulocyte-colony stimulating factor in HIV-associated pre-eclampsia}

The G-CSF glycoprotein plays a role in the mediation of neutrophil release in the blood stream (Figure 1.3). Additionally, high circulating levels of G-CSF result in neutrophils altering the body's immune system with an upregulation of inflammation (Cai et al., 2017). Furthermore, GCSF is also implicated in the increased release of monocytes which counteract the effect of an inflammatory response by releasing anti-inflammatory cytokines (Eyles et al., 2006). This antiinflammatory role of G-CSF is important in pregnancy because it temporarily suppresses an immune response by its effects on lymphocytes, macrophages and T helper-2 cells (Kamath et $a l ., 2017)$. In the exaggerated inflammatory milieu of PE, G-CSF would serve to lower the immune response. In HIV infected PE, G-CSF elevates levels of CD4+ T cell subset thereby inhibiting inflammatory infiltration (Peng, 2017). Nonetheless, there is a paucity of data on GCSF levels in HIV-associated PE. It is plausible to hypothesize that G-CSF may be implicated in an immunoregulatory and angiogenic role; hence be of diagnostic value for the early detection of PE. 


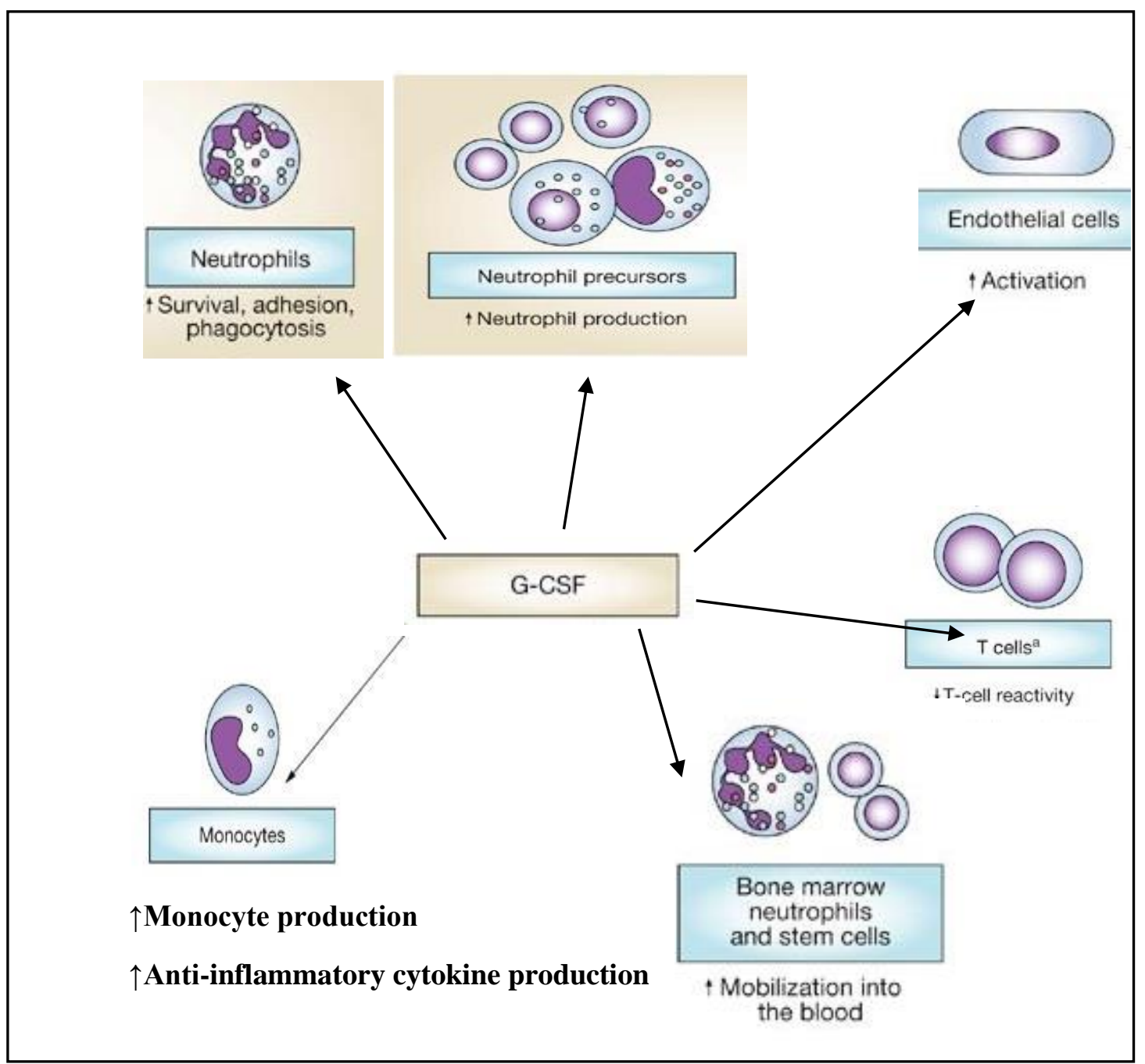

Figure 1.3: Diagram showing basic cellular activities of G-CSF. G-CSF promotes the release of neutrophils from the bone marrow into blood circulation. These neutrophils are involved in phagocytosis and the release of monocytes. G-CSF also acts on neutrophil precursors, increasing neutrophil production. More importantly, G-CSF increases the activation of endothelial cells. Circulating G-CSF plays an important role in an immune response by decreasing $\mathrm{T}$ cell reactivity. Adapted from Eyles et al. (2006). 


\subsection{Aim:}

To establish the role of FS and G-CSF in HIV-associated normotensive pregnancy and PE using the Bio-Plex Multiplex Immunoassay.

\subsection{Objectives:}

- To determine the effect of HIV status (HIV +ve $v s$ HIV -ve) on FS and G-CSF serum concentrations, irrespective of pregnancy type.

- To determine the effect of pregnancy type (normotensive $v s$ PE) on FS and G-CSF serum concentrations, irrespective of HIV status.

- To compare FS and G-CSF serum concentrations across the study population (HIV +ve normotensive pregnant, HIV -ve, normotensive pregnant, HIV +ve PE and HIV -ve PE)

- To correlate FS and G-CSF serum concentration with maternal age, gestational age, parity, blood pressure and maternal weight across the study population.

\subsection{Study rationale:}

Pre-eclampsia and HIV infection are the major causes of maternal mortality and morbidity cases in SA. In order to introduce treatment methods, it is important to understand the pathogenesis of HIV-associated PE and the role of FS and G-CSF in limiting the effects of both conditions. 
CHAPTER 2 
HYPERTENSION

IN

PREGNANCY

The role of follistatin and granulocyte-colony stimulating factor in HIV-associated pre-eclampsia.

\begin{tabular}{|c|c|}
\hline Journal: & Hyperterssion in Pregnancy \\
\hline Manuscript ID & Draft \\
\hline Manuscript Type: & Original Article \\
\hline $\begin{array}{r}\text { Date Submitted by the } \\
\text { Author: }\end{array}$ & $n / a$ \\
\hline Complete Lat of Authors: & $\begin{array}{l}\text { Molaloee, Slphesinle; University of KwaZulu-Natal College of Health } \\
\text { Sclences, Optics and Imaging } \\
\text { Moodley, Jagidesa; University of KwaZulu-Natal, Women's Health and } \\
\text { HIV Research Group } \\
\text { Naicker, Thajasvarbe; University of KwaZulu-Natal, Optics \& Imsging } \\
\text { Centre }\end{array}$ \\
\hline Keywords: & $\begin{array}{l}\text { Pre-eclampela, HIV, Follistatin, Granulocyte-colony stimulating factor, } \\
\text { HAART }\end{array}$ \\
\hline
\end{tabular}

56HOLARONE*

Manuscripts

URE: httpolmcmonuscriptcentralicom/ihip 


\section{THE ROLE OF FOLLISTATIN AND GRANULOCYTE-COLONY STIMULATING FACTOR IN HIV-ASSOCIATED PRE-ECLAMPSIA}

Siphesihle Mdlalose, Jagidesa Moodley ${ }^{\mathrm{a}}$ and Thajasvarie Naicker

Optics and Imaging Centre, Nelson R. Mandela School of Medicine, University of KwaZuluNatal, Durban, KwaZulu-Natal, South Africa

aWomen's Health and HIV Research Group, Department of Obstetrics and Gynaecology, Nelson R. Mandela School of Medicine, University of KwaZulu-Natal, Durban, KwaZuluNatal, South Africa

Corresponding author:

Mr. Siphesihle Mdlalose

Optics \& Imaging Centre,

Doris Duke Medical Research Institute,

Nelson R. Mandela School of Medicine,

University of KwaZulu-Natal

Durban, South Africa

Email address:217011521@stu.ukzn.ac.za;naickera@ukzn.ac.za;jmog@ukzn.ac.za 


\begin{abstract}
KZN has a high burden of HIV infection and high blood pressure, specifically pre-eclampsia (PE) in pregnancy. Follistatin (FS) and granulocyte-colony stimulating factor (G-CSF) are two glycoproteins involved in PE pathogenesis. In light of the high maternal mortality and morbidity in South Africa (SA), we investigated the expression of FS and G-CSF in the duality of HIVassociated PE. Serum samples of normotensive and pre-eclamptic women were analysed using the Bio-Plex Multiplex Immunoassay. FS expression was significantly reduced in pre-eclamptic compared to normotensive pregnancies $(649.5 \pm 116.8$ vs $2354 \pm 353.6 ; p<0.001)$. However, FS expression did not differ between HIV +ve vs HIV -ve groups (1727 \pm 291.2 vs 1305 \pm 306.7 ; $p=0.13$ ). Furthermore, we detected significant FS expression across all study groups. The expression of G-CSF was not affected by HIV status i.e., between HIV +ve vs HIV -ve groups $(14.4 \pm 2.3$ vs $11.6 \pm 0.7, p=0.10)$ and there was no significant difference between normotensive $v s$ pre-eclamptic groups $(14.9 \pm 2.4$ vs $11.3 \pm 0.5, p=0.32)$. G-CSF expression was notably higher in HIV +ve normotensive when compared to all study groups. This study demonstrated a downregulation of FS and G-CSF expression in PE, compared to normotensive pregnancies. This finding may be attributed to oxidative stress and its immunoregulatory role in the hyperinflammatory milieu of PE. HIV status had no effect on both analytes, albeit upregulated due to immune reconstitution emanating from HAART. Our novel findings suggest that FS and G-CSF may have a potential predictor test value in early pregnancy, hence work on this is ongoing.
\end{abstract}

Keywords: Pre-eclampsia, HIV, Follistatin, Granulocyte-colony stimulating factor, HAART

Running title: FS and G-CSF in HIV-associated pre-eclampsia.

Total word count: 3924

Word count excluding abstract and references: 2452

Number of figures: 2

Number of tables: 1 


\section{Introduction}

Globally, an estimated $75 \%$ of maternal deaths is attributed to haemorrhage, high blood pressure, abortions and non-pregnancy related infections such as malaria and human immunodeficiency virus (HIV) (1). More than 2 million HIV infected women become pregnant every year, with the majority residing in sub-Saharan Africa (2). In South Africa (SA) more than $21.7 \%$ of women are living with HIV and are at child bearing age (3).

Pre-eclampsia (PE) is a hypertensive disorder that affects up to $8 \%$ of all pregnancies annually (4). In SA, PE accounts for $14.8 \%$ of all maternal deaths (44). PE is identified by proteinuria, new-onset hypertension and poor placental perfusion in pregnant women (5). Moreover, trophoblast invasion is dysregulated and transformation of the spiral arteries is limited to the decidua during the first trimester of pregnancy (6). The consequence of this deficient invasion is reduced blood flow with subsequent poor foetal growth (7). The reduced blood flow results in an ischaemic placenta, which releases pro-inflammatory factors and generates an excess reactive oxygen species (ROS) into the maternal circulation (8). The resultant endothelial dysfunction contributes to the maternal syndrome, characterised as clinical symptoms of PE (9). Notably, ROS accumulation causes a self-perpetuating inflammatory response which causes chemical destruction and ultimately tissue degrading and cell death (10).

Follistatin (FS) is an extracellular glycoprotein which functions by preventing the ligand-receptor interaction of activin, which belongs to the transforming growth factor- $\beta$ (TGF- $\beta$ ) superfamily which are essential for regulating cell development and growth $(11,12)$. FS is also an important mediator of cell secretion, development and differentiation in numerous body systems (13). Moreover, FS plays an important immunoregulatory role in an inflammatory response (14). It is a protagonist in both an innate and humoral immune response, with previous studies implicating the protein in an immune response to viruses (15). Furthermore, FS is involved in angiogenesis (16).

Granulocyte-colony stimulating factor (G-CSF) is a $19.6 \mathrm{kDa}$ glycoprotein consisting of 4 antiparallel $\alpha$ helicases, originally identified in serum as it induced differentiation of the murine myelomonocytic leukemic cell line (17). Various tissues can produce G-CSF when stimulated by inflammatory mediators such as lipopolysaccharides (LPS), tumour necrosis factor- $\alpha$ (TNF- $\alpha$ ), vascular endothelial factor (VEGF), macrophages and fibroblasts (18). G-CSF serves as a growth factor that promotes the proliferation and differentiation of neutrophil progenitors (19). 
Additionally, G-CSF released in the blood stream stimulates the mobilization and production of neutrophils within the bone marrow (18). Like FS, G-CSF also promotes angiogenesis by inducing the proliferation of endothelial cells (20).

Despite literature demonstrating an upregulation of anti-angiogenic factors in PE, their implementation as a predictor test for PE development is poor in low income countries $(21,22)$. South Africa is the epicentre of the global HIV pandemic with a high prevalence of PE (12\%), hence it is imperative that the association of both conditions is investigated (44). In view of the fact that both FS and G-CSF play a role in the pathogenesis of PE, this study will examine their expression in women based on pregnancy type (normotensive $v s$ pre-eclamptic) and HIV status (HIV +ve vs HIV -ve).

\section{Materials and methods}

Ethical approval (BCA 338/17) and regulatory health authority permission were obtained prior to recruitment of study participants.

Study population: Black pregnant women $(n=80)$ were recruited at the Obstetric unit of a large regional hospital in Durban, SA and divided into 2 study groups viz., normotensive pregnant and pre-eclamptic women. These groups were further stratified by HIV status-into HIV +ve preeclamptic (n=20), HIV -ve pre-eclamptic ( $n=20)$, HIV +ve normotensive $(n=20)$ and HIV -ve normotensive $(\mathrm{n}=20)$.

Inclusion criteria: $\mathrm{PE}$ was defined as systolic blood pressure $\geq 140 \mathrm{mmHg}$ and diastolic blood pressure $\geq 90 \mathrm{mmHg}$ and proteinuria occurring after 20 weeks of gestation measured as $300 \mathrm{mg}$ of protein in a 24-hour urine sample or measured with a dipstick with a value $\geq 1+$, taken 4-6 hours apart. The HIV status was determined via a routine rapid test at a large regional hospital and CD4+ counts were performed if the woman was HIV +ve. All newly HIV +ve women were initiated on combined anti-retroviral therapy (ART).

Exclusion criteria: Women with chronic diabetes, gestational diabetes, chronic hypertension, connective tissue disorder, chronic renal disease, cardiac disease, sickle cell disease, polycystic ovarian syndrome, abruption placentae, intrauterine death, unknown HIV status, asthma, preexisting seizure disorders, patients with declined participation, unbooked patients and those who were unable to provide informed consent were excluded from the study. 
Sample collection: Following informed consent, venepuncture was used to obtain venous blood samples in K3-EDTA tubes. The samples were centrifuged at $1000 \mathrm{rpm}$ for $10 \mathrm{~min}$ at $4^{\circ} \mathrm{C}$. The layers were separated i.e. buffy coat, whole blood and serum and stored in cryovials at $-80^{\circ} \mathrm{C}$ until immunoassay.

Bio-plex Multiplex immunoassay: The buffy coat (leucocyte suspension) was used to assess differences in median fluorescent intensity (MFI) of phosphorylated FS (1:4 dilution) using the Bio-Plex ${ }^{\circledR}$ Pro $^{\mathrm{TM}}$ Human Cancer Biomarker Panel 1, 16-plex standards (catalogue\#171304055M; Bio-Rad Inc., South Africa). G-CSF (CSF-3) (1:1 dilution) was assessed using ProcartaPlex Human Basic Kit (lot\#168095000; Thermo Fisher Scientific., Austria). Both FS and G-CSF assays were performed according to the manufacturer's instructions (23) respectively. The assay followed a similar technique to that of a sandwich ELISA, following incubation of antigen samples to the study viz, FS and G-CSF with the capture antibody-coupled magnetic beads. Biotinylated detection antibodies were added to the reaction, along with reporter conjugate, streptavidinphycoerythrin conjugate (SA-PE). After washing, detection of the fluorescence of the SA-PE bound to each bead was carried out using the Bio-Plex ${ }^{\circledR M A G P I X}{ }^{\mathrm{TM}}$ Multiplex Reader (Bio-Rad Laboratories Inc., USA).

Data analysis: A protocol was generated on the Bio-Plex Manager ${ }^{\mathrm{TM}}$ software version 4.1, to obtain the data from the multiplex system. The measurement of analyte expression for a given bead population in each group was provided as the MFI, which is proportional to the concentration of the analyte bound to the reporter. A positive and negative cell lysate control was used for qualitative verification of the assay. The data was exported into an Excel spreadsheet for statistical analysis.

Statistical analysis: Data was analysed using GraphPad Prism 5.00 for windows (GraphPad Software, San Diego, California USA). Normality test used to check distribution of data (parametric or non-parametric). Data is represented as Mean \pm Standard Error of Mean. Statistical analysis across all groups of the same sample population were based on HIV status and pregnancy type, using the One-way ANOVA and the Bonferroni post-hoc multiple comparison test. The Mann Whitney's student t-test was performed for comparison between two groups e.g., HIV +ve vs HIV -ve or normotensive vs pre-eclamptic. The level of significance was considered as a probability level of $\mathrm{p}<0.05$. 


\section{Results}

\section{Clinical characteristics and patient demographic data}

There was no significant difference in maternal age across all study groups $(p=0.14)$. However, there was a significant difference in gestational age between HIV-ve normotensive (39.4 \pm 0.4 weeks) $v s$ HIV +ve pre-eclamptic $(31.1 \pm 0.9$ weeks $)(p<0.0001)$ and HIV +ve normotensive $v s$ HIV-ve pre-eclamptic $(p<0001)$. Additionally, there was no significant difference in parity $(p=0.25)$. As expected, a statistical significance was detected for both systolic blood pressure $(p<0.0001)$ and diastolic blood pressure $(p<0.0001)$ between the normotensive and pre-eclamptic group. There was no significant difference in maternal weight across all study groups ( $p=0.91)$.

\section{FS expression}

HIV status: Regardless of pregnancy type (normotensive vs pre-eclampsia), there was no significant difference in FS expression between HIV +ve and HIV-ve groups $(1727 \pm 291.2 v s$ $1305 \pm 306.7, p=0.13$; Figure 1A). The MFI of FS was upregulated in HIV infection, albeit nonsignificantly.

Pregnancy type: FS expression was significantly downregulated in pre-eclamptic compared to normotensive group, irrespective of HIV status (649.5 vs 2354 $\pm 353.6 \pm 116.8, p<0.001$; Figure 1B).

Across all groups: Figure 1C illustrates FS expression across all study groups. There was a significant difference in the expression of FS between the HIV -ve normotensive $v s$ HIV +ve preeclamptic group $(2105 \pm 552.8$ vs $802 \pm 213.6, p<0.01)$, HIV +ve normotensive $v s$ HIV +ve preeclamptic group $(2603 \pm 449.1$ vs $802 \pm 213.6, p<0.01)$ and HIV +ve normotensive $v s$ HIV -ve preeclamptic group $(2603 \pm 449.1$ vs $505.1 \pm 99.9, p<0.001)$. The expression of FS was highest in the HIV +ve normotensive group. 


\section{G-CSF expression}

HIV status: The expression of G-CSF was not affected by HIV status i.e., between HIV +ve vs HIV -ve groups (14.4 \pm 2.3 vs $11.6 \pm 0.7, p=0.10$; Figure 2A), irrespective of pregnancy type.

Pregnancy type: Regardless of HIV status, there was no significant difference in the MFI of GCSF between normotensive $v s$ pre-eclamptic groups (14.9 \pm 2.4 vs $11.3 \pm 0.5, p=0.32$; Figure 2B). Additionally, G-CSF was downregulated in the pre-eclamptic group.

Across all groups: Figure 2C illustrates G-CSF expression across all study groups. There was a significant difference between HIV -ve normotensive $v s$ HIV +ve normotensive groups (11.6 \pm 1.1 vs 18.2 $\pm 4.7, p<0.05$ ). The expression of G-CSF was highest in the HIV +ve normotensive group. Nonetheless, the expression of G-CSF was similar between the HIV -ve pre-eclamptic vs HIV + ve pre-eclamptic group $(11.5 \pm 0.8$ vs $11.1 \pm 0.6 p>0.05)$.

\section{Discussion}

This study demonstrates a significant downregulation of FS in PE, irrespective of HIV status. These findings are similar to previous studies who attributed this decline to the oxidative stress occurring in PE (24). Notably, the findings of (25) also supports FS downregulation in the hypoxic micro-environment of PE. In cultured human umbilical vein endothelial cells, activin induces ROS production through activating smad2/3 to increase NADPH oxidase 2 (NOX2) activity, which causes endothelial dysfunction (26). The presence of activin promotes ROS production and exacerbates PE development, while FS inhibits this process by neutralizing activin (24). In contrast, FS downregulates NOX2 protein levels to reduce the production of ROS, thus protecting endothelial cells (26). Moreover, FS has an angiogenic role and is strongly expressed in migrating endothelial cells (27). This migration activity of endothelial cells can be inhibited by activin however, FS neutralizes the effect of activin thus promoting angiogenesis (27). Notably, FS administration/infusion in a rat model with arterial damage was shown to reduce tissue damage and promote the repair process, highlighting the regenerative role of FS in post-ischemic injury (28). PE is associated with oxidative stress, high ROS production and anti-angiogenic imbalance. 
Hence, the observed downregulation of FS in our pre-eclamptic group compared to the normotensive group.

Based on HIV status, we report no significant difference in FS expression, irrespective of pregnancy type. There was however, an upregulatory trend of FS in HIV infection. Both activin and FS have immunoregulatory roles in an inflammatory response (14). In contrast to activin, FS has an anti-inflammatory response by direct inhibition of activin (29). The imbalance between activin and FS exaggerates the severity of the inflammatory state in diseases such as asthma and carcinogenesis (30). The release of activin precedes the release of other inflammatory cytokines, therefore the modulation of the activin and FS system is a potential therapeutic target in HIVassociated PE which has an inflammatory component (30). The non-significant difference in FS expression in this study may be attributed to the use of highly active antiretroviral therapy (HAART), a standard of care in all HIV infected patients in SA. The disparate immune response of PE and HIV infection would indicate a neutralisation. However, the introduction of HAART has resulted in an increased incidence of PE in HIV infected woman (31). HAART re-establishes immunocompetence thereby, exacerbating the exaggerated immune response of PE (32).

This study also reports a non-significant difference in the expression of G-CSF between the normotensive and pre-eclamptic group, regardless of HIV status; albeit a downregulation in the latter group. Endothelial cells, monocytes and endometrial cells produce G-CSF, which plays an important role in trophoblast invasion and placental metabolism (33). The downregulation of GCSF may be attributed to the deficient trophoblast invasion in PE, with resulting angiogenic imbalance (9). Nonetheless, there is a paucity of information on G-CSF serum levels in PE. However, G-CSF has a role in promoting angiogenesis in an animal model via a direct stimulatory action on mature endothelial cells $(20,34)$. A study conducted by (35) showed G-CSF directly stimulates endothelial cell-like network formation on Matrix gel culture in vitro. In light of the latter findings, the downregulation of G-CSF observed in our study is predictable, as PE is an anti-angiogenic state (8).

It is worth mentioning that the administration of G-CSF to healthy individuals or experimental animals results in neutrophilia (36). Neutrophils are responsible for the production of inflammatory cytokines such as interlukin-8 (37). These neutrophils infiltrate the vasculature of women with PE and provide a chemotactic gradient that attracts more neutrophils (38). The neutrophils will subsequently infiltrate into the intimal spaces where they release ROS consequently resulting in inflammation (38). Moreover, (39) showed that a high dosage of G-CSF is associated with an upregulation of inflammation. The unexpected downregulation of G-CSF in PE is attributed to the use of HAART, which re-establishes immunocompetence. In pregnancy, 
G-CSF temporarily suppresses the immune response by its effect on lymphocytes, macrophages and $\mathrm{T}$ helper-2 cells (33). This immune response suppression is to prevent an exacerbated inflammatory response, such as the one observed in PE.

In our study, there was no significant difference detected in the expression of G-CSF between HIV +ve and HIV -ve groups. However, in the HIV +ve group there was an upregulation of GCSF expression when compared to the HIV-ve group. The HIV +ve group will have a drop in their CD4+ count as a result of the HIV infection (40). However, the upregulation of G-CSF in the HIV +ve group is to combat the CD4+ drop by increasing the percentage of CD4+ regulatory $\mathrm{T}$ cells (41). Moreover, the use of HAART reconstitutes the maternal immune response. This suggests that G-CSF upregulation in the HIV +ve group is to elicit its anti-inflammatory properties (44). Previous studies show that in vitro, G-CSF decreases lipopolysaccharide-induced secretion of pro-inflammatory cytokines by increasing the activity of monocytes (36). This consequently results in the increased release of anti-inflammatory cytokines (43). These antiinflammatory cytokines are to combat the duality of HIV and PE with the adverse effects of HAART.

\section{Limitations}

The study was limited by a small sample size and non-inclusion of other ethnicities. The use of HAART may have influenced the expression of our analytes however, further studies are required.

\section{Conclusion}

This study demonstrates a downregulation of FS and G-CSF expression in PE, possibly due to oxidative stress and the anti-angiogenic micro-environment of PE. In addition, a limitation of the study was the small sample size. These novel findings suggest that both FS and G-CSF have potential predictor test value for early diagnosis of PE development. HIV status did not influence FS and G-CSF expression, this may be attributed to the effects of the HAART regimen adopted in SA. It is also plausible to assume that the upregulation of FS and G-CSF expression (albeit non-significant) in the HIV +ve group, arises as a result of the immune response in controlling viral infection. Further studies will interrogate FS and G-CSF levels across the trimesters of pregnancy and introduce a larger sample size. 


\section{Declaration of interest}

There are no conflicts of interest.

\section{Acknowledgments}

The study was funded by the College of Health Sciences, UKZN and the National Research Foundation. 
1. Say L, Chou D, Gemmill A, Tunçalp Ö, Moller A-B, Daniels J, et al. Global causes of maternal death: a WHO systematic analysis. The Lancet Global Health. 2014; 2(6):323-333.

2. Moodley J, Pattinson RC, Baxter C, Sibeko S, Abdool Karim Q. Strengthening HIV services for pregnant women: an opportunity to reduce maternal mortality rates in Southern Africa/sub-Saharan Africa. BJOG: An International Journal of Obstetrics \& Gynaecology. 2010; 118(2):219-225.

3. Statistics SA. Mid-year population estimates. South Africa, Private Bag X44, Pretoria 0001; 201823 July 2018; 1-26.

4. Yong HEJ, Murthi P, Brennecke SP, Moses EK. Genetic Approaches in Preeclampsia. Methods in molecular biology (Clifton, NJ). 2018; 1710:53-72.

5. Thakoordeen S, Moodley J, Naicker T. Candidate Gene, Genome-Wide Association and Bioinformatic Studies in Pre-eclampsia: a Review. Curr Hypertens Rep. 2018; 20(10):91.

6. Salman H, Shah M, Ali A, Aziz A, Vitale SG. Assessment of Relationship of Serum Neurokinin-B Level in the Pathophysiology of Pre-eclampsia: A Case-Control Study. Advances in Therapy. 2018; 35(7):1114-1121.

7. Gathiram P, Moodley J. Pre-eclampsia: its pathogenesis and pathophysiolgy: review articles. Cardiovascular journal of Africa. 2016; 27(2):71-78.

8. Chaiworapongsa T, Chaemsaithong P, Yeo L, Romero R. Pre-eclampsia part 1: current understanding of its pathophysiology. Nature Reviews Nephrology. 2014; 10:466.

9. Ngene NC, Moodley J. Role of angiogenic factors in the pathogenesis and management of pre-eclampsia. International Journal of Gynecology \& Obstetrics. 2017; 141(1):5-13.

10. Trogstad L, Magnus P, Stoltenberg C. Pre-eclampsia: Risk factors and causal models. Best Practice \& Research Clinical Obstetrics \& Gynaecology. 2011; 25(3):329-342.

11. Flanagan JN, Linder K, Mejhert N, Dungner E, Wahlen K, Decaunes P, et al. Role of Follistatin in Promoting Adipogenesis in Women. The Journal of Clinical Endocrinology \& Metabolism. 2009; 94(8):3003-3009.

12. Blumenfeld Z, Ritter M. Inhibin, Activin, and Follistatin in Human Fetal Pituitary and Gonadal Physiology. Annals of the New York Academy of Sciences. 2001; 943(1):34-48. 
13. Sidis Y, Schneyer AL, Sluss PM, Johnson LN, Keutmann HT. Follistatin: essential role for the N-terminal domain in activin binding and neutralization. The Journal of biological chemistry. 2001; 276(21):17718-17726.

14. Refaat B, El-Shemi AG, Ashshi AM, AlZanbagi A. Serum Activins and Follistatin during the Treatment of Chronic Hepatitis C Genotypes 1 and 4 and Their Correlations with Viral Load and Liver Enzymes: A Preliminary Report. Gastroenterology Research and Practice. 2014; 2014:628-683.

15. Werner S, Alzheimer C. Roles of activin in tissue repair, fibrosis, and inflammatory disease. Cytokine Growth Factor Rev. 2006; 17(3):157-171.

16. Kelaini S, Vilà-González M, Caines R, Campbell D, Eleftheriadou M, Tsifaki M, et al. Follistatin-Like 3 Enhances the Function of Endothelial Cells Derived from Pluripotent Stem Cells by Facilitating $\beta$-Catenin Nuclear Translocation Through Inhibition of Glycogen Synthase Kinase-3 $\beta$ Activity. STEM CELLS. 2018; 36(7):1033-1044.

17. Schneider A, Kuhn G, Schäbitz W-R. A role for G-CSF (Granulocyte Colony Stimulating Factor) in the central nervous system2006. 1753-1757.

18. Bendall LJ, Bradstock KF. G-CSF: From granulopoietic stimulant to bone marrow stem cell mobilizing agent. Cytokine \& Growth Factor Reviews. 2014; 25(4):355-367.

19. Basu S, Hodgson G, Katz M, Dunn AR. Evaluation of role of G-CSF in the production, survival, and release of neutrophils from bone marrow into circulation. Blood. 2002; 100(3):854.

20. Kohlstedt K, Trouvain C, Frömel T, Mudersbach T, Henschler R, Fleming I. Role of the angiotensin-converting enzyme in the G-CSF-induced mobilization of progenitor cells. Basic Research in Cardiology. 2018; 113(3):18.

21. Maynard SE, Karumanchi SA. Angiogenic factors and preeclampsia. Semin Nephrol. 2011; 31(1):33-46.

22. Sibai B, Dekker G, Kupferminc M. Pre-eclampsia. The Lancet. 2005; 365(9461):785799.

23. http://www.bio-rad.com.

24. Zhang L, Liu K, Han B, Xu Z, Gao X. The emerging role of follistatin under stresses and its implications in diseases. Gene. 2018; 639:111-116. 
25. Garces MF, Vallejo SA, Sanchez E, Palomino-Palomino MA, Leal LG, Angel-Muller E, et al. Longitudinal analysis of maternal serum Follistatin concentration in normal pregnancy and preeclampsia. Clinical endocrinology. 2015; 83(2):229-235.

26. Lim R, Acharya R, Delpachitra P, Hobson S, Sobey CG, Drummond GR, et al. Activin and NADPH-oxidase in preeclampsia: insights from in vitro and murine studies. American journal of obstetrics and gynecology. 2015; 212(1):86.e1-12.

27. Gerritsen ME. Chapter 8 - Angiogenesis A2 - Tuma, Ronald F. In: Durán WN, Ley K, editors. Microcirculation (Second Edition). San Diego: Academic Press; 2008. p. 351-383.

28. Welt C, Sidis Y, Keutmann H, Schneyer A. Activins, inhibins, and follistatins: From endocrinology to signaling. A paradigm for the new millennium2002. 724-752 p.

29. Miyamoto T, Carrero JJ, Qureshi AR, Anderstam B, Heimbürger O, Bárány P, et al. Circulating follistatin in patients with chronic kidney disease: implications for muscle strength, bone mineral density, inflammation, and survival. Clinical Journal of the American Society of Nephrology. 2011; 6(5):1001-1008.

30. Hardy JT, Buhimschi IA, McCarthy ME, Zhao G, Laky CA, Shook LL, et al. Imbalance of Amniotic Fluid Activin-A and Follistatin in Intraamniotic Infection, Inflammation, and Preterm Birth. The Journal of Clinical Endocrinology \& Metabolism. 2016; 101(7):2785-2793.

31. Phoswa WN, Naicker T, Ramsuran V, Moodley J. Pre-eclampsia: the role of highly active antiretroviral therapy and immune markers. Inflammation research: official journal of the European Histamine Research Society [et al]. 2018; 2018:1-11.

32. Kalumba V, Moodley J, Naidoo T. Is the prevalence of pre-eclampsia affected by HIV/AIDS? A retrospective case-control study: cardiovascular topics. Cardiovascular journal of Africa. 2013; 24(2):24-27.

33. Kamath MS, Chittawar PB, Kirubakaran R, Mascarenhas M. Use of granulocyte-colony stimulating factor in assisted reproductive technology: A systematic review and meta-analysis. European Journal of Obstetrics \& Gynecology and Reproductive Biology. 2017; 214:16-24.

34. Natori T, Sata M, Washida M, Hirata Y, Nagai R, Makuuchi M. G-CSF stimulates angiogenesis and promotes tumor growth: potential contribution of bone marrow-derived endothelial progenitor cells. Biochem Biophys Res Commun. 2002; 297(4):1058-1061. 
35. Lee M, Aoki M, Kondo T, Kobayashi K, Okumura K, Komori K, et al. Therapeutic Angiogenesis With Intramuscular Injection of Low-Dose Recombinant Granulocyte-Colony Stimulating Factor. Arteriosclerosis, Thrombosis, and Vascular Biology. 2005; 25(12):25-35.

36. Jeannin P, Paolini L, Adam C, Delneste Y. The roles of CSFs on the functional polarization of tumor-associated macrophages. The FEBS Journal. 2018; 285(4):680-699.

37. Rosales C, Lowell CA, Schnoor M, Uribe-Querol E. Neutrophils: Their Role in Innate and Adaptive Immunity 2017. Journal of Immunology Research. 2017; 2017:1-2.

38. Pinheiro MB, Martins-Filho OA, Mota APL, Alpoim PN, Godoi LC, Silveira ACO, et al. Severe preeclampsia goes along with a cytokine network disturbance towards a systemic inflammatory state. Cytokine. 2013; 62(1):165-173.

39. Cai J, Li B, Liu K, Feng J, Gao K, Lu F. Low-dose G-CSF improves fat graft retention by mobilizing endogenous stem cells and inducing angiogenesis, whereas high-dose G-CSF inhibits adipogenesis with prolonged inflammation and severe fibrosis. Biochemical and Biophysical Research Communications. 2017; 491(3):662-667.

40. Poulton M. Aetiology and pathology of HIV and AIDS. Stroke. 2018; 13:57.

41. Peng W. G-CSF treatment promotes apoptosis of autoreactive $\mathrm{T}$ cells to restrict the inflammatory cascade and accelerate recovery in experimental allergic encephalomyelitis. Experimental Neurology. 2017; 289:73-84.

42. Martins A, Han J, Kim SO. The multifaceted effects of granulocyte colony-stimulating factor in immunomodulation and potential roles in intestinal immune homeostasis. IUBMB life. 2010; 62(8):611-617.

43. Eyles JL, Roberts AW, Metcalf D, Wicks IP. Granulocyte colony-stimulating factor and neutrophils-forgotten mediators of inflammatory disease. Nature Clinical Practice Rheumatology. 2006; 2:1-500.

44. Department of Health. Saving mothers 2014-2016: (2017). Seventh triennial report on confidential enquiries into maternal deaths in South Africa: executive summary. Republic of South Africa: National Department of Health, 1-134. 

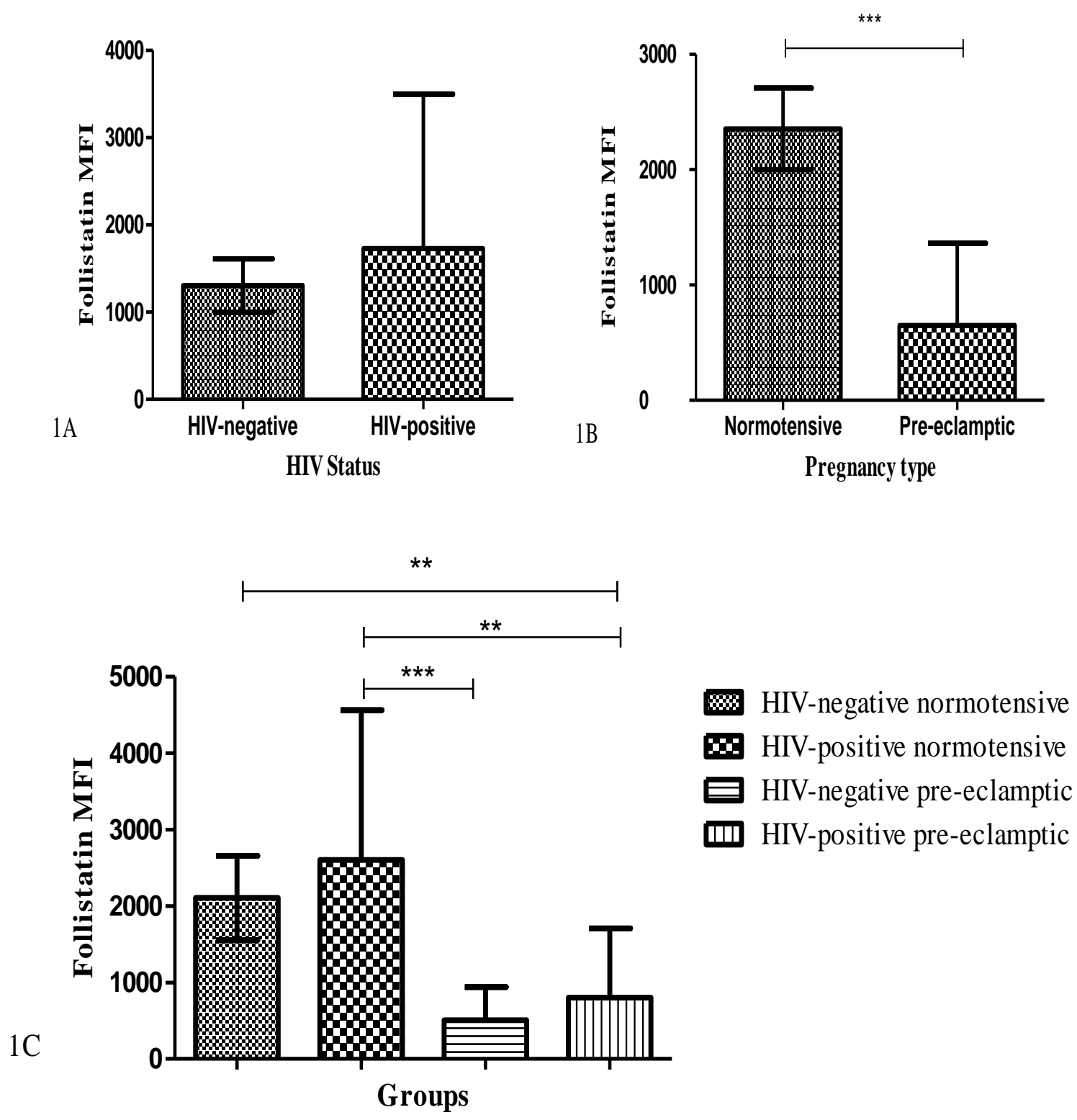

Figure 1: FS expression: (A) based on HIV status; no significance (ns) (B) based on pregnancy type; $* * * p<0.001$ and $(\mathrm{C})$ across all study groups; $* * \boldsymbol{p}<0.01 * * * p<0.001$. Results are represented as mean \pm SEM. 
Graph 2A error bars adjusted.
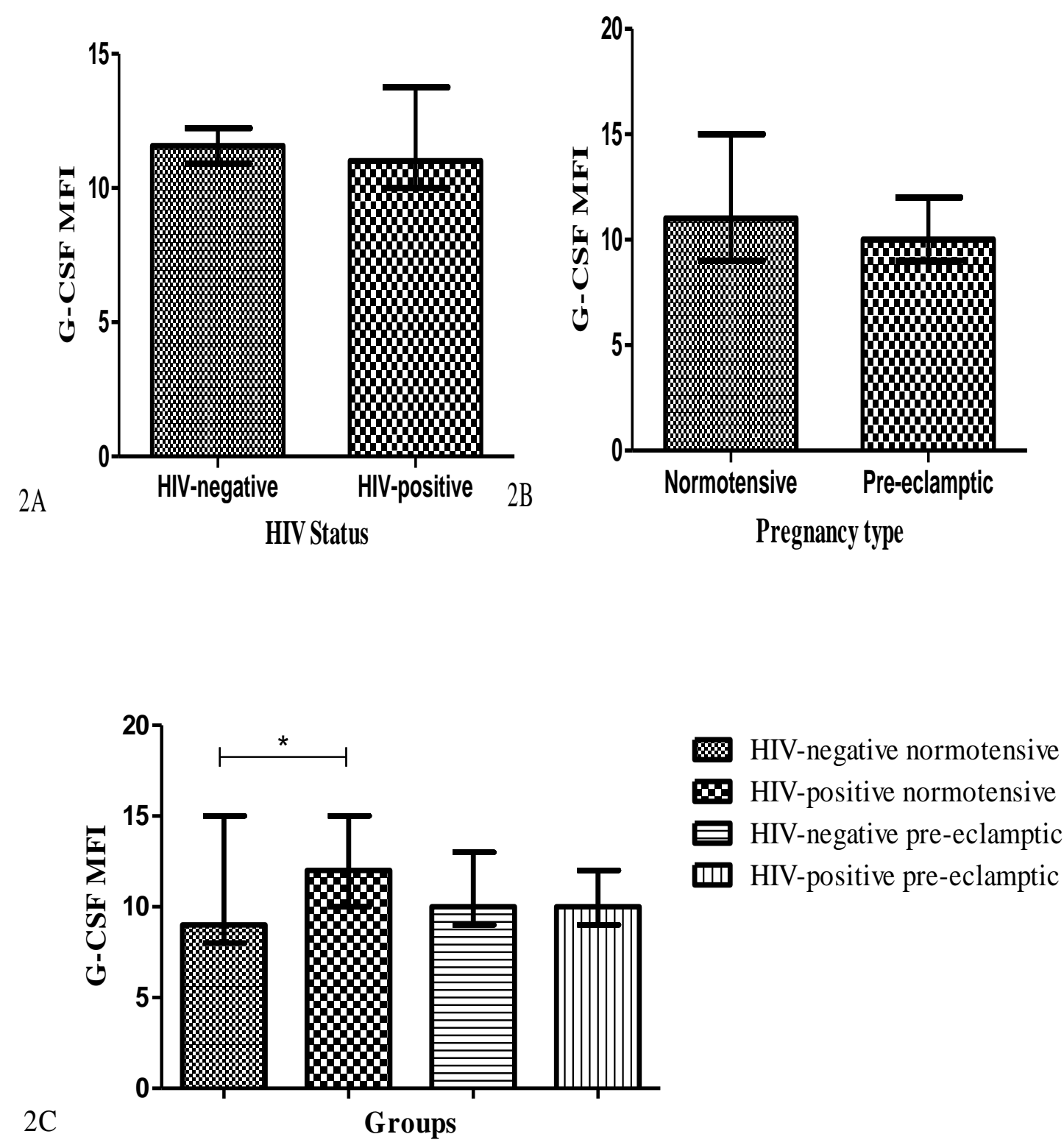

Figure 2: G-CSF expression: (A) based on HIV status; no significance (ns) (B) based on pregnancy type; no significance (ns) and (C) across all study groups; ${ }^{*} p<0.05$. Results are represented mean \pm SEM. 
Table 1: Clinical demographic results. Mean \pm SEM are represented; One-way ANOVA and the Bonferroni post hoc multiple comparison test was used for statistical analysis, $\mathrm{n}=\mathbf{8 0}$

\begin{tabular}{|c|c|c|c|c|c|}
\hline & $\begin{array}{c}\text { HIV }-\mathrm{ve} \\
\text { normotensive } \\
\mathrm{n}=20\end{array}$ & $\begin{array}{c}\text { HIV +ve } \\
\text { normotensive } \\
\mathrm{n}=20\end{array}$ & $\begin{array}{c}\text { HIV -ve } \\
\text { pre-eclamptic } \\
\mathrm{n}=20\end{array}$ & $\begin{array}{c}\text { HIV +ve } \\
\text { pre-eclamptic } \\
\mathrm{n}=20\end{array}$ & p-value \\
\hline $\begin{array}{c}\text { Maternal } \\
\text { Age }\end{array}$ & $25 \pm 1$ & $29 \pm 1$ & $26 \pm 2$ & $29 \pm 6$ & $p=0.14$ \\
\hline $\begin{array}{c}\text { Gestational } \\
\text { Age }\end{array}$ & $39 \pm 0.4$ & $38.5 \pm 0.5$ & $33 \pm 1$ & $31 \pm 1$ & $p<0.0001$ \\
\hline Parity & $1 \pm 0.3$ & $1.5 \pm 0.2$ & $1 \pm 0.2$ & $1.3 \pm 0.2$ & $p=0.25$ \\
\hline $\begin{array}{c}\text { Systolic BP } \\
\text { (mmHg) }\end{array}$ & $120 \pm 2$ & $114.6 \pm 3$ & $159 \pm 4$ & $164 \pm 3$ & $p<0.0001$ \\
\hline $\begin{array}{c}\text { Diastolic BP } \\
\text { (mmHg) }\end{array}$ & $67 \pm 2$ & $67.4 \pm 2.0$ & $104.4 \pm 2$ & $107 \pm 2$ & $p<0.0001$ \\
\hline $\begin{array}{c}\text { Maternal } \\
\text { Weight (kg) }\end{array}$ & $77 \pm 3$ & $76 \pm 4$ & $77 \pm 5$ & $77 \pm 6$ & $p=0.91$ \\
\hline
\end{tabular}


CHAPTER 3 


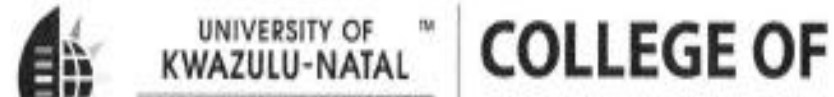 INYUVESI
YAKWAZULU-NATALI HEALTH SCIENCES}

Annual Research Symposium

11-12 $2^{\text {th }}$ October 2018

K-RITH Tower Building

Nelson R Mandela School of Medicine Campus 


\title{
THE ROLE OF FOLLISTATIN IN HIV-ASSOCIATED PRE-ECLAMPSIA
}

\author{
Siphesihle Mdlalose_, Thajasvarie Naicker
}

Optics and Imaging

\section{Introduction}

KwaZulu-Natal has a high burden of HIV infection and high blood pressure, specifically pre-eclampsia (PE) in pregnancy. Follistatin (FS) is an extracellular glycoprotein antagonist of the ligand receptor, Activin-A, involved in PE pathogenesis. In light of the high maternal mortality and morbidity in SA, we investigated the expression of FS in the duality of HIV associated PE.

\section{Method}

Serum samples of normotensive and pre-eclamptic women stratified by HIV status were collected from a large regional hospital in Durban, and their FS expression was analysed using the Bio-Plex Multiplex Immunoassay.

\section{Results}

Irrespective of HIV status, FS expression was significantly reduced in pre-eclamptic compared to normotensive pregnancies (2354 353.6 vs $649.5 \pm 116.8 ; \mathrm{p}<0.001)$. However, FS expression did not differ between HIV +ve vs HIV -ve groups ( $1727 \pm 291.2$ vs $1305 \pm 306.7 ; p=0.13$ )- regardless of pregnancy type. Furthermore, we detected significant FS expression across all study groups ( $\mathrm{p}>0.05$ ).

\section{Conclusion}

This study demonstrates a downregulation of FS expression in PE, possibly due to oxidative stress and its immunoregulatory role in the hyperinflammatory milieu of PE. Moreover, the fact that FS did not vary by HIV status may be attributed to the effects of HAART regimen adopted in SA. It is also plausible to assume that the upregulation of FS expression (albeit non-significant) in HIV +ve patients, arises as a result of the immune response in controlling viral infection. Our novel findings suggest that FS may have a potential predicator test value early in pregnancy, hence work on this is ongoing. 


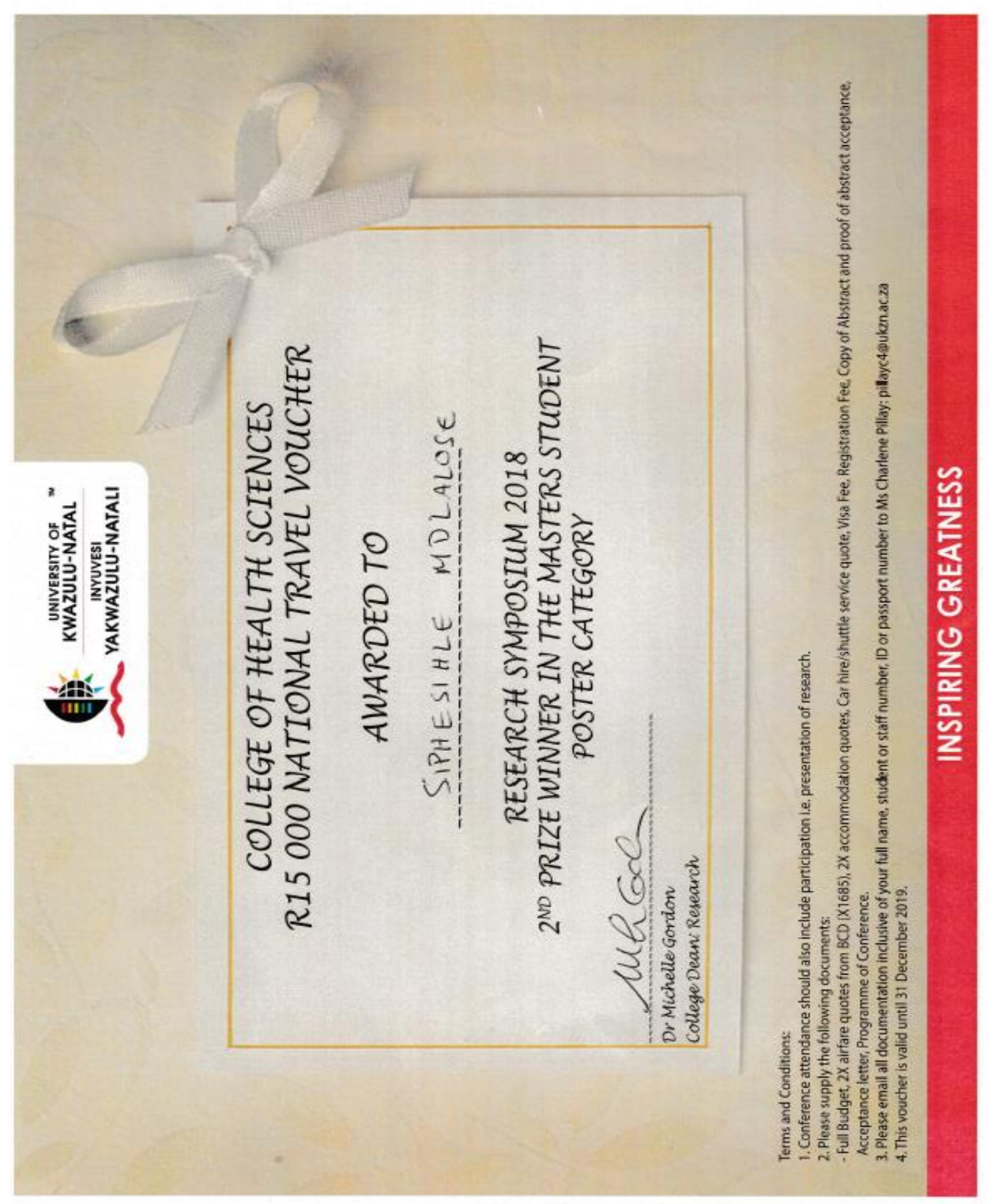




\section{Luminex.}

complexity simplified.

Mr. Siphesihle Mdlalose

Department of 0ptics and Imaging

Laboratory Medicine and Medical Sciences

Nelsen R. Mandela School of Medicine

College of Health Sciences

University of KwaZulu-Natal

Dear Mr. Mdlalose,

We are happy to inform you your abstract is accepted for a poster presentation during xMAP® Connect 2018 Amsterdam.

This event takes place on November $6^{\text {th }}$ and November $7^{\text {th }} 2018$ at the following location:

Royal Tropical Institute

Mauritskade 63

1092 AD Amsterdam

The Netherlands

We look forward to your poster presentation during XMAP ${ }^{\circledR}$ Connect Amsterdam.

Kind regards,

Thomas Pracht

Managing Director

Luminex EMEIA 


\section{conterenceserenteseun Gynecology and Ohstetrics Pathology}

\section{Abstract Acceptance Letter}

To

Mr. Siphesihle Mdlalose,

Department of Optics and Imaging

Laboratory Medicine and Medical

Sciences,

University of KwaZulu-Natal

South Africa
November 19-20, 2018 | Poris, France

\section{Date:}

October 25, 2018

Your Abstract entitled "The role if follistatin in HIV-associated pre-eclampsia" has been accepted for Poster Presentation at " $2{ }^{\text {nd }}$ International Meeting on Gynecology and Obstetrics Pathology 2018 (Gynecology and Obstetrics Pathology 2018)" scheduled on November 19-20, 2018 at Paris, France.

Conference Series LLC Ltd, the World Class Open Access Publisher and Scientific Events Organizer is delighted to cordially welcome you to join us and share your presentation of about 15-20 mints in respective to the theme "Unveiling the Breakthroughs that Improve Women's Health and Quality of Life". Conference Series LLC Ltd was established in the year 2007 and at present has pioneered the scientific world by publishing articles in about 400 Open Access Journals, conducting over 300 Scientific Meetings and numerous B2B Meetings.

We are looking forward to see you at Paris, France.

For more details please visit our website for Gynecology and Obstetrics Pathology 2018

https://gynecology-obstetrics.pathologyconferences.com/

With our best wishes,

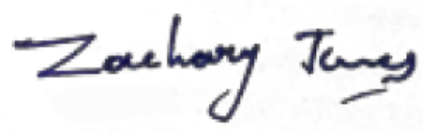

Mr. Zachary Jones

Sr. Manager

$2^{\text {nd }}$ International Meeting on Gynecology and Obstetrics Pathology

Conference Series LLC Ltd

47 Churchfield Road

W3 6AY London, UK

Office +44-0-800-014-8923 
Introduction: KwaZulu-Natal has a high burden of HIV infection and high blood pressure, specifically pre-eclampsia (PE) in pregnancy. Follistatin (FS) is an extracellular glycoprotein antagonist of the ligand receptor, Activin-A, involved in PE pathogenesis. In light of the high maternal mortality and morbidity in SA, we investigated the expression of FS in the duality of HIV-associated PE.

Method: Serum samples of normotensive and pre-eclamptic women stratified by HIV status were collected from a large regional hospital in Durban, and their FS expression was analysed using the Bio-Plex Multiplex Immunoassay.

Results: Irrespective of HIV status, FS expression was significantly reduced in preeclamptic compared to normotensive pregnancies $(649.5 \pm 116.8$ vs 2354 \pm 353.6 ; $p<0.001)$. However, FS expression did not differ between HIV +ve vs HIV -ve groups $(1727 \pm 291.2$ vs $1305 \pm 306.7$; $p=0.13)$ - regardless of pregnancy type. Furthermore, we detected significant FS expression across all study groups $(p>0.05)$.

Conclusion: This study demonstrates a downregulation of FS expression in PE, possibly due to oxidative stress and its immunoregulatory role in the hyperinflammatory milieu of PE. Moreover, the fact that FS did not vary by HIV status may be attributed to the effects of HAART regimen adopted in SA. It is also plausible to assume that the upregulation of FS expression (albeit non-significant) in HIV +ve patients, arises as a result of the immune response in controlling viral infection. Our novel findings suggest that FS may have a potential predicator test value early in pregnancy, hence work on this is ongoing. 
CHAPTER 4 


\section{SYNTHESIS}

Maternal mortality within the African continent is high, with sub-Saharan Africa accounting for $85 \%$ of the maternal mortality rate (Amzat, 2015). Whilst pregnancy places most women at a higher risk for a pregnancy-related event, some women are at higher risk of mortality than others (Hirshberg and Srinivas, 2017). More than $75 \%$ of pregnancy related deaths are caused by hypertension and HIV, so clarification of the interaction in the duality of these conditions is imperative (Say et al., 2014). There are more than 2 million pregnancies in HIV infected women worldwide, with the majority occurring within sub-Saharan Africa (Moodley et al., 2010). In SA, one-fifth of women in their reproductive ages are HIV +ve (Statistics, 2018). Furthermore, hypertensive disorders such as PE contribute directly to maternal deaths occurring in SA (Moodley, 2010). Notably, PE accounts for $14.8 \%$ of all maternal deaths occurring within SA (Saving mothers 2014-2016, 2017).

Globally, PE affects 5-7\% of pregnancies, with immunological and genetic factors implicated in its pathogenesis (Salman et al., 2018). A defective trophoblast and the non-physiological conversion of myometrial spiral arteries contributes to placental ischaemia and the ensuing hypoxia which characterizes PE (Chaiworapongsa et al., 2014). Moreover, an angiogenic imbalance in favour of elevated anti-angiogenic factors such as sFlt1 and sEng exist in PE together with a concomitant downregulation of pro-angiogenic factors [PIGF and VEGF] (Maynard and Karumanchi, 2011;Ngene and Moodley, 2017).

This study demonstrates a downregulation of FS in PE compared to the normotensive pregnant groups, irrespective of HIV status. These findings are corroborated by Zhang et al. (2018) who attributed the decline of FS to the high oxidative stressed micro-environment of PE. Similarly a longitudinal analysis also showed that serum FS levels are lower in women with PE compared to normotensive pregnant women (Garces et al., 2015). FS is a glycosylated single-chain protein observed in the inhibition of FSH secretion (Kelaini et al., 2018). The local role of FS is to neutralize the effect of activin by binding to its receptor thereby restricting activin bioavailability for stimulation of FSH (Keutmann et al., 2004). In PE, serum activin is significantly higher compared to normotensive pregnant women (Yu et al., 2011). Moreover, in PE- activin induces oxidative stress via the activation of $\operatorname{smad} 2 / 3$ promoting the release of NADPH oxidase 2 (NOX2), causing a hypoxic environment that results in FS downregulation (Zhang et al., 2018). Furthermore, FS plays a role in tissue restoration and is involved in endothelial cell differentiation, including angiogenesis (Kelaini et al., 2018). It is well established that an 
angiogenic disproportion in favour of anti-vs pro-angiogenic state prevails in PE (Gathiram and Moodley, 2016). Since FS is a pro-angiogenic molecule, the downregulation of FS in PE is plausible, in view of the decreased angiogenesis (Turcotte et al., 2017). Additionally, our findings are supported by Charkiewicz et al. (2018) who reported that pro-angiogenic factors (VEGF and PIGF) are downregulated, with a concurrent significant decline in FS expression in women with PE.

In contrast, a study conducted by Founds et al. (2015) described an upregulation of follistatinlike 3 (FSL3) over the course of pregnancy in women who subsequently developed PE. This was attributed to the higher insulin resistance in PE and/or to the effects of hypoxia. Results are contradictory in that enhanced serum FS levels have been reported in PE compared to normotensive pregnant women (Keelan et al., 2002). However, D'Antona et al. (2000) reported the inverse.

This current study reports a non-significant difference albeit, an upwards trend in FS between the HIV +ve compared to the HIV -ve group, irrespective of pregnancy type. In HIV infection there is a loss of CD4+ cells and the suppression of the immune system (Poulton, 2018). Klein et al. (1996) showed that FS levels increased in sheep after the administration of LPS, illustrating the role of FS in the acute phase of an inflammatory response .Moreover, FS administration to mice reduces the levels of LPS, suggesting that FS has an anti-inflammatory effect (Hansen and Plomgaard, 2016). Notably, the anti-inflammatory effect of FS has been shown in patients with sepsis (Phillips et al., 2001).

Moreover, inflammation related to hypoxia induces activin, which increases FSL3 transcription via the smad proteins (Founds et al., 2015). Activin is expressed within inflammatory cells, promoting an inflammatory response (Monsuur et al., 2018). The latter studies suggest that in an HIV infection, FS expression would be increased to neutralize the effects of activin. Confounding our results, is the fact that a standard of care practice in SA is HAART. This standard of care induces immune reconstitution in HIV infected pre-eclamptic women (Phoswa et al., 2018). This implies that serum levels of activin would rise to elicit a systemic inflammatory response that is exacerbated in PE. The interaction of activin with smad proteins and the stimulation of nitric oxide metabolites is inhibited by the upregulation of FS (Phillips et al., 2001). Therefore, we hypothesize that the FS upregulation in HIV +ve pre-eclamptic woman is a compensatory mechanism to neutralize the effects of activin, a release stimulated by the immune reconstitution effect of HAART. 
In our study, there was no significant difference in the expression of G-CSF between the preeclamptic vs normotensive group, irrespective of HIV status. However, there was an observed down regulatory trend of G-CSF in PE. G-CSF is a glycoprotein that induces the differentiation of myelomocytic leukemic cell line (Schneider et al., 2006). The G-CSF receptor is a single homodimer receptor which mediates the effects of G-CSF (Bendall and Bradstock, 2014). This receptor signals via STAT3, STAT5 and the MAPK cell signalling pathways (Hamilton et al., 2016). It is plausible that STAT3 is downregulated in HIV infection negatively influencing dendritic cell function, thereby interfering with the mechanism that links innate and adaptive immunity.

Literature suggests that G-CSF promotes angiogenesis inducing the proliferation of endothelial cells (Kohlstedt et al., 2018). Lee et al. (2005), showed that recombinant G-CSF when administrated in low doses effectively augments ischaemia, inducing angiogenesis in vivo. G-CSF and VEGF mobilize endothelial cells from the bone marrow into peripheral circulation and promote angiogenesis (Okazaki et al., 2006). In PE, the angiogenic imbalance in favour of antiangiogenic factors $v s$ pro-angiogenic factors (G-CSF) results in endothelial dysfunction (Kalumba et al., 2013).

Notably, endothelial cells produce G-CSF, since PE is characterized by endothelial dysfunction there will be a downregulation in G-CSF production. This was observed in our study as G-CSF was downregulated in the pre-eclamptic group. The production of G-CSF can be induced in vitro by TNF- $\alpha$, IL-1 and bacterial LPS (Daniels and Lewin, 2008). These cytokines are present in pre-eclamptic women as a result of oxidative stress eventuating in an increase in G-CSF. The GCSF downregulation noted in our study could be attributed to HAART as it reconstitutes the maternal immune response.

Furthermore, G-CSF expression in our study were similar between HIV +ve vs HIV -ve groups, regardless of pregnancy type. G-CSF plays an important role in the mediation of neutrophil release in the blood stream, with neutropenia being associated with an upregulation of inflammation (Cai et al., 2017). The presence of G-CSF in the blood stream alters the body's immune system, eliciting an immune response to an infection (Basu et al., 2002). Studies have highlighted the beneficial effects of G-CSF after it has been administrated in different inflammatory conditions (Jeannin et al., 2018). A study conducted by Martins et al. (2010) showed that G-CSF has anti-inflammatory properties in vitro and in vivo. In addition, Boneberg et al. (2000) showed that in vitro, G-CSF decreases LPS-induced secretion of pro-inflammatory 
cytokines by increasing mobilization of human monocytes. This suggests that G-CSF has an antiinflammatory role by increasing the activation of monocytes, which release anti-inflammatory cytokines (Eyles et al., 2006). Notably, in mice G-CSF mobilizes CD34+ progenitors which favour T-regulatory cell expansion, protecting the mice from developing type 1 diabetes (Kared et al., 2005).

Our study demonstrated that G-CSF has an upregulatory trend in the HIV +ve group compared to the HIV -ve group. Since HIV infection is characterized by the drop in an HIV infected individuals CD4+ count, mice who were administrated with G-CSF showed an increased percentage of CD4+ regulatory T cells (Peng, 2017;Poulton, 2018). Hence in HIV infection, the compensatory action of G-CSF would be to promote an immune response. Nonetheless, HAART establishes an individual's immune response thus, the upregulation of G-CSF in HIV infection is to mobilize CD4+ cells.

In conclusion, this study reports the downregulation of FS and G-CSF in PE compared to normotensive pregnancies reflecting the anti-angiogenic state of PE. Both FS and G-CSF were upregulated albeit non-significantly in HIV infection, due to their immunoregulatory role in both innate and adaptive response. However, HAART may have affected analyte expression due to immune reconstitution in HIV infection further exacerbating the immune response of PE.

Future studies will include a larger sample size, stratification of the PE group by gestational age and the consideration of the duration of HAART. 
CHAPTER 5 


\section{REFERENCES}

ABALOS, E., CUESTA, C., GROSSO, A. L., CHOU, D. \& SAY, L. 2013. Global and regional estimates of preeclampsia and eclampsia: a systematic review. Eur J Obstet Gynecol Reprod Biol, 170, 1-7.

AGIUS, A., SUlTANA, R., CAMENZULI, C., CALLEJA-AGIUS, J. \& BALZAN, R. 2018. An update on the genetics of pre-eclampsia. Minerva ginecologica, 70, 465-479.

AMZAT, J. 2015. The Question of Autonomy in Maternal Health in Africa: A Rights-Based Consideration. Journal of Bioethical Inquiry, 12, 283-293.

ANASTASILAKIS, A. D., POLYZOS, S. A., SKOUVAKLIDOU, E. C., KYNIGOPOULOS, G., SARIDAKIS, Z. G., APOSTOLOU, A., TRIANTAFYLlOU, G. A., KARAGIOZOGLOU-LAMPOUDI, T. \& MANTZOROS, C. S. 2016. Circulating follistatin displays a day-night rhythm and is associated with muscle mass and circulating leptin levels in healthy, young humans. Metabolism, 65, 1459-1465.

BASU, S., HODGSON, G., KATZ, M. \& DUNN, A. R. 2002. Evaluation of role of G-CSF in the production, survival, and release of neutrophils from bone marrow into circulation. Blood, 100, 854.

BENDALL, L. J. \& BRADSTOCK, K. F. 2014. G-CSF: From granulopoietic stimulant to bone marrow stem cell mobilizing agent. Cytokine \& Growth Factor Reviews, 25, 355-367.

BLUMENFELD, Z. \& RITTER, M. 2001. Inhibin, Activin, and Follistatin in Human Fetal Pituitary and Gonadal Physiology. Annals of the New York Academy of Sciences, 943, $34-48$.

BONEBERG, E. M., HARENG, L., GANTNER, F., WENDEL, A. \& HARTUNG, T. 2000. Human monocytes express functional receptors for granulocyte colony-stimulating factor that mediate suppression of monokines and interferon-gamma. Blood, 95, 270-276.

CAI, J., LI, B., LIU, K., FENG, J., GAO, K. \& LU, F. 2017. Low-dose G-CSF improves fat graft retention by mobilizing endogenous stem cells and inducing angiogenesis, whereas high- 
dose G-CSF inhibits adipogenesis with prolonged inflammation and severe fibrosis. Biochemical and Biophysical Research Communications, 491, 662-667.

CHAIWORAPONGSA, T., CHAEMSAITHONG, P., YEO, L. \& ROMERO, R. 2014. Preeclampsia part 1: current understanding of its pathophysiology. Nature Reviews Nephrology, 10, 466.

CHARKIEWICZ, K., JASINSKA, E., GOSCIK, J., KOC-ZORAWSKA, E., ZORAWSKI, M., KUC, P., RABA, G., KLUZ, T., KALINKA, J., SAKOWICZ, A. \& LAUDANSKI, P. 2018. Angiogenic factor screening in women with mild preeclampsia - New and significant proteins in plasma. Cytokine, 106, 125-130.

D'ANTONA, D., REIS, F. M., BenEDetTo, C., EVANS, L. W., GROOME, N. P., DE KRETSER, D. M., WALLACE, E. M. \& PETRAGLIA, F. 2000. Increased maternal serum activin A but not follistatin levels in pregnant women with hypertensive disorders. J Endocrinol, 165, 157-162.

DANIELS, K. \& LEWIN, S. 2008. Translating research into maternal health care policy: a qualitative case study of the use of evidence in policies for the treatment of eclampsia and pre-eclampsia in South Africa. Health Research Policy and Systems, 6, 12.

DELLAR, R. C., DLAMINI, S. \& KARIM, Q. A. 2015. Adolescent girls and young women: key populations for HIV epidemic control. J Int AIDS Soc, 18, 19408.

DEPARTMENT OF HEALTH. SAVING MOTHERS 2014-2016: (2017). Seventh triennial Report on confidential enquiries into maternal deaths in South Africa: executive summary. Republic of South Africa: National Department of Health, 1-134.

ENGLISH, F. A., KENNY, L. C. \& MCCARTHY, F. P. 2015. Risk factors and effective management of preeclampsia. Integrated Blood Pressure Control, 8, 7-12.

EYLES, J. L., ROBERTS, A. W., METCALF, D. \& WICKS, I. P. 2006. Granulocyte colonystimulating factor and neutrophils—-forgotten mediators of inflammatory disease. Nature Clinical Practice Rheumatology, 2, 500. 
FLANAGAN, J. N., LINDER, K., MEJHERT, N., DUNGNER, E., WAHLEN, K., DECAUNES, P., RYDÉN, M., BJÖRKLUND, P., ARVER, S., BHASIN, S., BOULOUMIE, A., ARNER, P. \& DAHLMAN, I. 2009. Role of Follistatin in Promoting Adipogenesis in Women. The Journal of Clinical Endocrinology \& Metabolism, 94, 3003-3009.

FOUNDS, S. A., REN, D., ROBERTS, J. M., JEYABALAN, A. \& POWERS, R. W. 2015. Follistatin-Like 3 Across Gestation in Preeclampsia and Uncomplicated Pregnancies Among Lean and Obese Women. Reproductive Sciences, 22, 402-409.

GARCES, M. F., VALLEJO, S. A., SANCHEZ, E., PALOMINO-PALOMINO, M. A., LEAL, L. G., ANGEL-MULLER, E., DIAZ-CRUZ, L. A., RUIZ-PARRA, A. I., GONZALEZClaviJo, A. M., CASTANO, J. P., ABBA, M., LACUNZA, E., DIEGUEZ, C., NOGUEIRAS, R. \& CAMINOS, J. E. 2015. Longitudinal analysis of maternal serum Follistatin concentration in normal pregnancy and preeclampsia. Clin Endocrinol (Oxf), $83,229-235$.

GATHIRAM, P. \& MOODLEY, J. 2016. Pre-eclampsia : its pathogenesis and pathophysiolgy : review articles. Cardiovascular Journal of Africa, 27, 71-78.

GERRITSEN, M. E. 2008. Chapter 8 - Angiogenesis A2 - Tuma, Ronald F. In: DURÁN, W. N. \& LEY, K. (eds.) Microcirculation (Second Edition). San Diego: Academic Press, 8, 351383.

HAMILTON, J. A., COOK, A. D. \& TAK, P. P. 2016. Anti-colony-stimulating factor therapies for inflammatory and autoimmune diseases. Nat Rev Drug Discov, 16, 53-70.

HANSEN, J. S. \& PLOMGAARD, P. 2016. Circulating follistatin in relation to energy metabolism. Molecular and Cellular Endocrinology, 433, 87-93.

HARDY JT, BUHIMSCHI IA, MCCARTHY ME, ZHAO G, LAKY CA, SHOOK LL, et al. Imbalance of Amniotic Fluid Activin-A and Follistatin in Intraamniotic Infection, Inflammation, and Preterm Birth. The Journal of Clinical Endocrinology \& Metabolism. 2016; 101(7):2785-2793. 
HEDGER, M. P., WINNALL, W. R., PHILLIPS, D. J. \& DE KRETSER, D. M. 2011. The regulation and functions of activin and follistatin in inflammation and immunity. Vitam Horm, 85, 255-297.

HIRSHBERG, A. \& SRINIVAS, S. K. 2017. Epidemiology of maternal morbidity and mortality. Seminars in Perinatology, 41, 332-337.

HOGAN, M. C., FOREMAN, K. J., NAGHAVI, M., AHN, S. Y., WANG, M., MAKELA, S. M., LOPEZ, A. D., LOZANO, R. \& MURRAY, C. J. L. 2010. Maternal mortality for 181 countries, 1980-2008: a systematic analysis of progress towards Millennium Development Goal 5. The Lancet, 375, 1609-1623.

HUTCHEON, J. A., LISONKOVA, S. \& JOSEPH, K. S. 2011. Epidemiology of pre-eclampsia and the other hypertensive disorders of pregnancy. Best Practice \& Research Clinical Obstetrics \& Gynaecology, 25, 391-403.

JEANNIN, P., PAOLINI, L., ADAM, C. \& DELNESTE, Y. 2018. The roles of CSFs on the functional polarization of tumor-associated macrophages. The FEBS Journal, 285, 680699.

KALUMBA, V. M. S., MOODLEY, J. \& NAIDOO, T. D. 2013. Is the prevalence of preeclampsia affected by HIV/AIDS? A retrospective case-control study. Cardiovascular Journal of Africa, 24, 24-27.

KAMATH, M. S., CHITTAWAR, P. B., KIRUBAKARAN, R. \& MASCARENHAS, M. 2017. Use of granulocyte-colony stimulating factor in assisted reproductive technology: A systematic review and meta-analysis. European Journal of Obstetrics \& Gynecology and Reproductive Biology, 214, 16-24.

KARED, H., MASSON, A., ADLE-BIASSETTE, H., BACH, J. F., CHATENOUD, L. \& ZAVALA, F. 2005. Treatment with granulocyte colony-stimulating factor prevents diabetes in NOD mice by recruiting plasmacytoid dendritic cells and functional CD4(+)CD25(+) regulatory T-cells. Diabetes, 54, 78-84. 
KARUMANCHI, S. A. 2016. Angiogenic Factors in Preeclampsia. Hypertension, 67, 1072.

KEELAN, J. A., TAYLOR, R., SCHELLENBERG, J. C., GROOME, N. P., MITCHELL, M. D. \& NORTH, R. A. 2002. Serum activin A, inhibin A, and follistatin concentrations in preeclampsia or small for gestational age pregnancies. Obstet Gynecol, 99, 267-274.

KELAINI, S., VILÀ-GONZÁLEZ, M., CAINES, R., CAMPBELL, D., ELEFTHERIADOU, M., TSIFAKI, M., MAGEE, C., COCHRANE, A., O'NEILL, K., YANG, C., STITT, A. W., ZENG, L., GRIEVE, D. J. \& MARGARITI, A. 2018. Follistatin-Like 3 Enhances the Function of Endothelial Cells Derived from Pluripotent Stem Cells by Facilitating $\beta$ Catenin Nuclear Translocation Through Inhibition of Glycogen Synthase Kinase-3 $\beta$ Activity. STEM CELLS, 36, 1033-1044.

KEUTMANN, H., SCHNEYER, A. \& SIDIS, Y. 2004. The Role of Follistatin Domains in Follistatin Biological Action. Molecular Endocrinology, 18(1): 228-240.

KHALIQ, O. P., KONOSHITA, T., MOODLEY, J. \& NAICKER, T. 2018. The Role of Uric Acid in Preeclampsia: Is Uric Acid a Causative Factor or a Sign of Preeclampsia? Curr Hypertens Rep, 20, 80.

KLEIN, R., CLARKE, I. J., HEDGER, M. P. \& ROBERTSON, D. M. 1996. Plasma follistatin concentrations increase following lipopolysaccharide administration in sheep. Clin Exp Pharmacol Physiol, 23, 754-755.

KOHLSTEDT, K., TROUVAIN, C., FRÖMEL, T., MUDERSBACH, T., HENSCHLER, R. \& FLEMING, I. 2018. Role of the angiotensin-converting enzyme in the G-CSF-induced mobilization of progenitor cells. Basic Research in Cardiology, 113, 18.

LEE, M., AOKI, M., KONDO, T., KOBAYASHI, K., OKUMURA, K., KOMORI, K. \& MUROHARA, T. 2005. Therapeutic Angiogenesis With Intramuscular Injection of LowDose Recombinant Granulocyte-Colony Stimulating Factor. Arteriosclerosis, Thrombosis, and Vascular Biology, 25, 25-35.

LIM R, ACHARYA R, DELPACHITRA P, HOBSON S, SOBEY CG, DRUMMOND GR, et al. Activin and NADPH-oxidase in preeclampsia: insights from in vitro and murine studies. 
American journal of obstetrics and gynaecology. 2015; 212(1):86.e1-12.

MALAZA, A., MOSSONG, J., BÄRNIGHAUSEN, T. \& NEWELL, M.-L. 2012. Hypertension and Obesity in Adults Living in a High HIV Prevalence Rural Area in South Africa. PLOS ONE, 7, e47761.

MARTINS, A., HAN, J. \& KIM, S. O. 2010. The multifaceted effects of granulocyte colonystimulating factor in immunomodulation and potential roles in intestinal immune homeostasis. IUBMB Life, 62, 611-617.

MAYNARD, S. E. \& KARUMANCHI, S. A. 2011. Angiogenic Factors and Preeclampsia. Seminars in nephrology, 31, 33-46.

MIYAMOTO, T., CARRERO, J. J., QURESHI, A. R., ANDERSTAM, B., HEIMBÜRGER, O., BÁRÁNY, P., LINDHOLM, B. \& STENVINKEL, P. 2011. Circulating follistatin in patients with chronic kidney disease: implications for muscle strength, bone mineral density, inflammation, and survival. Clinical Journal of the American Society of Nephrology, 6, 1001-1008.

MONSUUR, H. N., VAN DEN BROEK, L. J., KOOLWIJK, P., NIESSEN, F. B. \& GIBBS, S. 2018. Endothelial cells enhance adipose mesenchymal stromal cell-mediated matrix contraction via ALK receptors and reduced follistatin: Potential role of endothelial cells in skin fibrosis. Journal of Cellular Physiology, 233, 6714-6722.

MOODLEY, J. 2010. Maternal deaths associated with eclampsia in South Africa: Lessons to learn from the confidential enquiries into maternal deaths, 2005 - 2007. S Afr Med J, 100, 717 719.

MOODLEY, J., FAWCUS, S. \& PATTINSON, R. 2018. Improvements in maternal mortality in South Africa. South African Medical Journal, 108, 4-8.

MOODLEY, J., PATTINSON, R. C., BAXTER, C., SIBEKO, S. \& ABDOOL KARIM, Q. 2010. Strengthening HIV services for pregnant women: an opportunity to reduce maternal 
mortality rates in Southern Africa/sub-Saharan Africa. BJOG: An International Journal of Obstetrics \& Gynaecology, 118, 219-225.

NATORI, T., SATA, M., WASHIDA, M., HIRATA, Y., NAGAI, R. \& MAKUUCHI, M. 2002. G-CSF stimulates angiogenesis and promotes tumor growth: potential contribution of bone marrow-derived endothelial progenitor cells. Biochem Biophys Res Commun, 297, 1058-1061.

NGENE, N. C. \& MOODLEY, J. 2017. Role of angiogenic factors in the pathogenesis and management of pre-eclampsia. International Journal of Gynecology \& Obstetrics, 141, 5-13.

OKAZAKI, T., EBIHARA, S., ASADA, M., KANDA, A., SASAKI, H. \& YAMAYA, M. 2006. Granulocyte colony-stimulating factor promotes tumor angiogenesis via increasing circulating endothelial progenitor cells and Gr1+CD11b+ cells in cancer animal models. International Immunology, 18, 1-9.

OKOYE, A. A. \& PICKER, L. J. 2013. CD4(+) T cell depletion in HIV infection: mechanisms of immunological failure. Immunological reviews, 254, 54-64.

PENG, W. 2017. G-CSF treatment promotes apoptosis of autoreactive T cells to restrict the inflammatory cascade and accelerate recovery in experimental allergic encephalomyelitis. Experimental Neurology, 289, 73-84.

PHILLIPS, D. J., JONES, K. L., SCHEERLINCK, J.-P. Y., HEDGER, M. P. \& DE KRETSER, D. M. 2001. Evidence for activin A and follistatin involvement in the systemic inflammatory response. Molecular and Cellular Endocrinology, 180, 155-162.

PHOSWA, W. N., NAICKER, T., RAMSURAN, V. \& MOODLEY, J. 2018. Pre-eclampsia: the role of highly active antiretroviral therapy and immune markers. Inflamm Res. 2018: 111.

PINHEIRO, M. B., MARTINS-FILHO, O. A., MOTA, A. P. L., ALPOIM, P. N., GODOI, L. C., SILVEIRA, A. C. O., TEIXEIRA-CARVALHO, A., GOMES, K. B. \& DUSSE, L. M. 
2013. Severe preeclampsia goes along with a cytokine network disturbance towards a systemic inflammatory state. Cytokine, 62, 165-173.

POULTER, N. R., PRABHAKARAN, D. \& CAULFIELD, M. 2015. Hypertension. The Lancet, $386,801-812$.

POULTON, M. 2018. Aetiology and pathology of HIV and AIDS. Stroke, 13, 57.

REFAAT, B., EL-SHEMI, A. G., ASHSHI, A. M. \& ALZANBAGI, A. 2014. Serum Activins and Follistatin during the Treatment of Chronic Hepatitis C Genotypes 1 and 4 and Their Correlations with Viral Load and Liver Enzymes: A Preliminary Report. Gastroenterology Research and Practice, 2014, 628-683.

ROSALES C, LOWELL CA, SCHNOOR M, URIBE-QUEROL E. Neutrophils: Their Role in Innate and Adaptive Immunity 2017. Journal of Immunology Research. $2017 ; 2017: 1-2$.

SALMAN, H., SHAH, M., ALI, A., AZIZ, A. \& VITALE, S. G. 2018. Assessment of Relationship of Serum Neurokinin-B Level in the Pathophysiology of Pre-eclampsia: A Case-Control Study. Advances in Therapy, 35, 1114-1121.

SAY, L., CHOU, D., GEMMILl, A., TUNÇAlP, Ö., MOLlER, A.-B., DANIELS, J., GÜLMEZOGLU, A. M., TEMMERMAN, M. \& ALKEMA, L. 2014. Global causes of maternal death: a WHO systematic analysis. The Lancet Global Health, 2, 323-333.

SCHNEIDER, A., KUHN, G. \& SCHÄBITZ, W.-R. 2006. A role for G-CSF (Granulocyte Colony Stimulating Factor) in the central nervous system. Cell Cycle 4:12, 1753-1757.

SEBASTIANI, G., DÍAZ, M., LÓPEZ-BERMEJO, A., ARRANZ, A., ZEGHER, F. \& IBÁÑEZ, L. 2011. Circulating follistatin in the human foetus at term birth. Pediatric Obesity, 7, 3943.

SIBAI, B., DEKKER, G. \& KUPFERMINC, M. 2005. Pre-eclampsia. The Lancet, 365, 785-799. 
SIDIS, Y., SCHNEYER, A. L., SLUSS, P. M., JOHNSON, L. N. \& KEUTMANN, H. T. 2001. Follistatin: essential role for the N-terminal domain in activin binding and neutralization. J Biol Chem, 276, 17718-17726.

STATISTICS, S. A. 2018. Mid-year population estimates. South Africa, Private Bag X44, Pretoria 0001. 2018, 1-26.

SUY, A., MARTÍNEZ, E., COLL, O., LONCA, M., PALACIO, M., DE LAZZARI, E., LARROUSSE, M., MILINKOVIC, A., HERNÁNDEZ, S., BLANCO, J. L., MALLOLAS, J., LEÓN, A., VANRELL, J. A. \& GATELL, J. M. 2006. Increased risk of pre-eclampsia and fetal death in HIV-infected pregnant women receiving highly active antiretroviral therapy. AIDS, 20:59-66.

THAKOORDEEN S, MOODLEY J, NAICKER T. Candidate Gene, Genome-Wide Association And Bioinformatics Studies in Pre-eclampsia: a Review. Current Hypertension Rep. 2018; 20(10):91.

TROGSTAD, L., MAGNUS, P. \& STOLTENBERG, C. 2011. Pre-eclampsia: Risk factors and causal models. Best Practice \& Research Clinical Obstetrics \& Gynaecology, 25, 329342.

TURCOTTE, L. M., DEFOR, T. E., NEWELL, L. F., CUTLER, C. S., VERNERIS, M. R., WU, J., HOWARD, A., MACMILlAN, M. L., ANTIN, J. H., VERCELlOTTI, G. M., SLUNGAARD, A., BLAZAR, B. R., WEISDORF, D. J., PANOSKALTSIS-MORTARI, A. \& HOLTAN, S. G. 2017. Donor and recipient plasma follistatin levels are associated with acute GvHD in Blood and Marrow Transplant Clinical Trials Network 0402. Bone Marrow Transplantation, 53, 64.

UNAIDS (2018) ‘UNAIDS GLOBAL STATISTICS 2018’, (July), pp. 1-5. Available at: http://www.unaids.org/sites/default/files/media_asset/UNAIDS_FactSheet_en.pdf. 
WANG, A., RANA, S. \& KARUMANCHI, S. A. 2009. Preeclampsia: the role of angiogenic factors in its pathogenesis. Physiology (Bethesda), 24, 147-158.

WELT, C., SIDIS, Y., KEUTMANN, H. \& SCHNEYER, A. 2002. Activins, inhibins, and follistatins: From endocrinology to signaling. A paradigm for the new millennium. Exp Biol Med, 227: 724.

WERNER, S. \& ALZHEIMER, C. 2006. Roles of activin in tissue repair, fibrosis, and inflammatory disease. Cytokine Growth Factor Rev, 17, 157-171.

WHO 2018. Maternal Mortality. Statistics obtained from website.

YONG HEJ, MURTHI P, BRENNECKE SP, MOSES EK. Genetic Approaches in Preeclampsia. Methods in molecular biology (Clifton, NJ). 2018; 1710:53-72.

YU, J., SHIXIA, C. Z., WU, Y. \& DUAN, T. 2011. Inhibin A, activin A, placental growth factor and uterine artery Doppler pulsatility index in the prediction of pre-eclampsia. Ultrasound Obstet Gynecol, 37, 528-533.

ZHANG, L., LIU, K., HAN, B., XU, Z. \& GAO, X. 2018. The emerging role of follistatin under stresses and its implications in diseases. Gene, 639, 111-116.

http://www.bio-rad.com. Website showing protocol of Immunoassay. 
CAHPTER 6 


\section{APPENDICES}

\section{APPENDICE 1: BREC APPROVAL}

17 April 2018

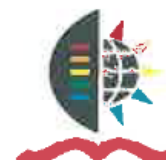

UNIVERSITY OF KWAZULU-NATAL

INYUVES!

YAKWAZULU-NATALI

RESEARCH OFFICE

Biomedical Research Ethics Administration Westville Campus, Govan Mbeki Building

Private Bag X 54001
Durban

KwaZulu-Natal, SOUTH AFRICA

Tel: 27312604769 - Fax: 27312604609

Website: http; //research. ukzn. ac.za/Research-Ethics/Biomedical-Research-Ethics. aspx

Prof T Naicker

Discipline of Optics and Imaging

School of Laboratory Medicine and Medical Sciences

naickera@ukzn.ac.za

\section{Dear Prof Naicker}

Title of Project: Exploring the pathogenesis HIV associate pre-eclampsia syndrome in a homogenous South African population group.

BREC Ref No.: BCA338/17

We wish to advise you that your response received on 03 April 2018 to BREC letter dated 16 March 2018 has been noted by a sub-committee of the Biomedical Research Ethics Committee.

Your request received on 07 March 2018 to append the studies below to the above study has now been approved by a sub-committee of the Biomedical Research Ethics Committee

\begin{tabular}{|l|l|l|}
\hline Name & Student number & Title \\
\hline Deneshree Varaden & 211510564 & $\begin{array}{l}\text { Morphometric image analysis of placental clec2d and } \\
\text { HLA-G immunolocalization in HIV-associated pre- } \\
\text { eclampsia }\end{array}$ \\
\hline Merantha Moodley & 214514757 & $\begin{array}{l}\text { The role of histone 2A in NETosis of HIV-associated pre- } \\
\text { eclampsia }\end{array}$ \\
\hline Kyle Kupsamy & 214504430 & EGF and HGF in HIV-associated pre-eclampsia \\
\hline Mikaila Moodley & 214558958 & $\begin{array}{l}\text { Immunoglobulin isotypes (IgG1, IgG2, IgG3, IgG4, IgM, } \\
\text { IgA) in HIV-associated pre-eclampsia }\end{array}$ \\
\hline Sangany & 211559876 & $\begin{array}{l}\text { The role of acidic and basic fibroblast growth factor in } \\
\text { HIV-associated pre-eclampsia }\end{array}$ \\
\hline Mduduzi Mazibuko & 214504614 & $\begin{array}{l}\text { The role of sTIE2 and sHER2 in HIV-associated pre- } \\
\text { eclampsia }\end{array}$ \\
\hline Siphesihle Mdlalose & 217011521 & $\begin{array}{l}\text { The role of follistatin and G-CSF in HIV-associated pre- } \\
\text { eclampsia }\end{array}$ \\
\hline
\end{tabular}

This approval will be ratified at the next BREC meeting to be held on 08 May 2018.

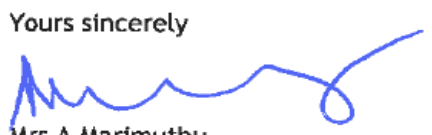

Mrs A Marimuthu

Senior Administrator: Biomedical Research Ethics 
APPENDICE 2: Follistatin standard curve

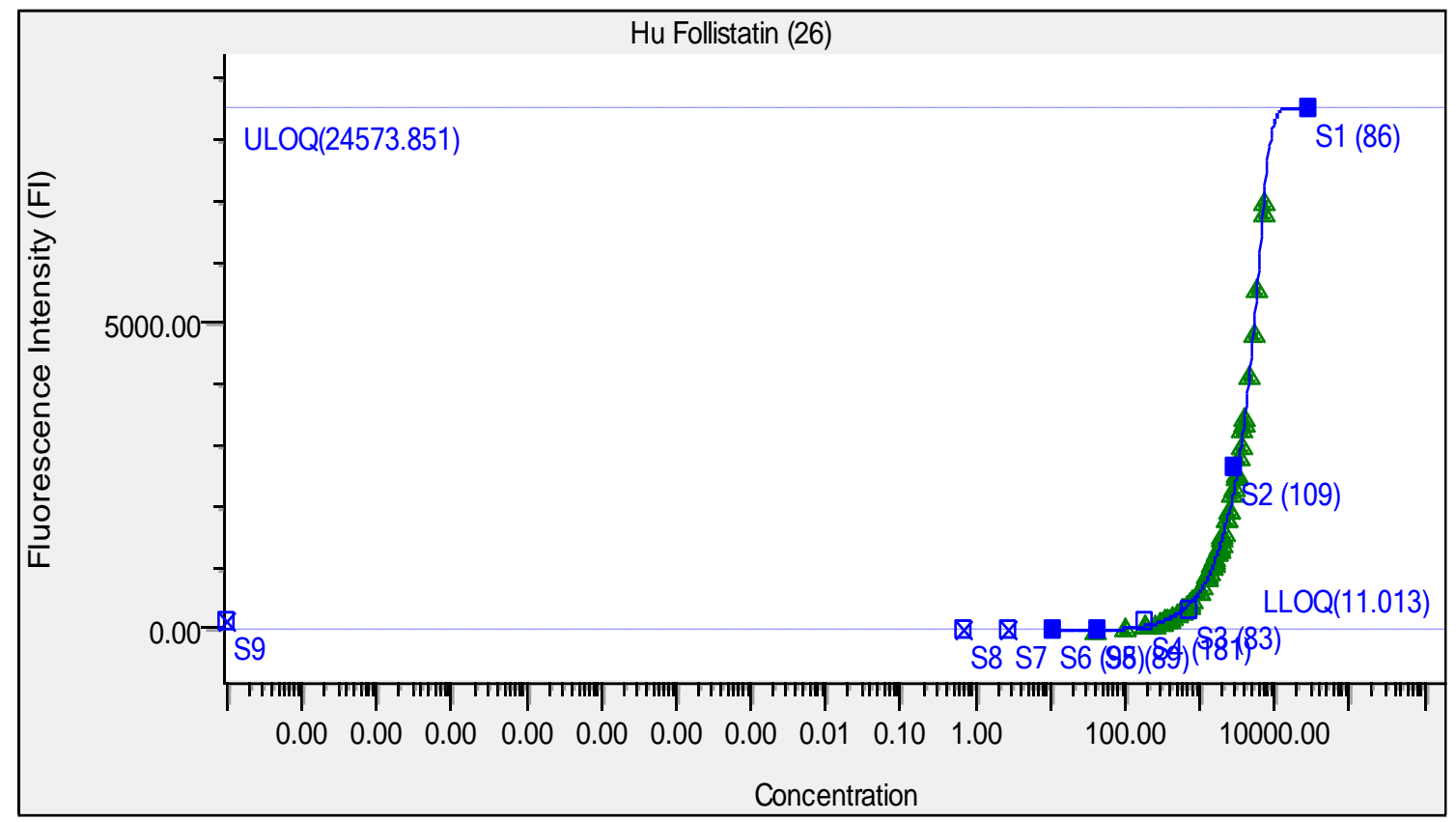

\section{APPENDICE 3: G-CSF standard curve}

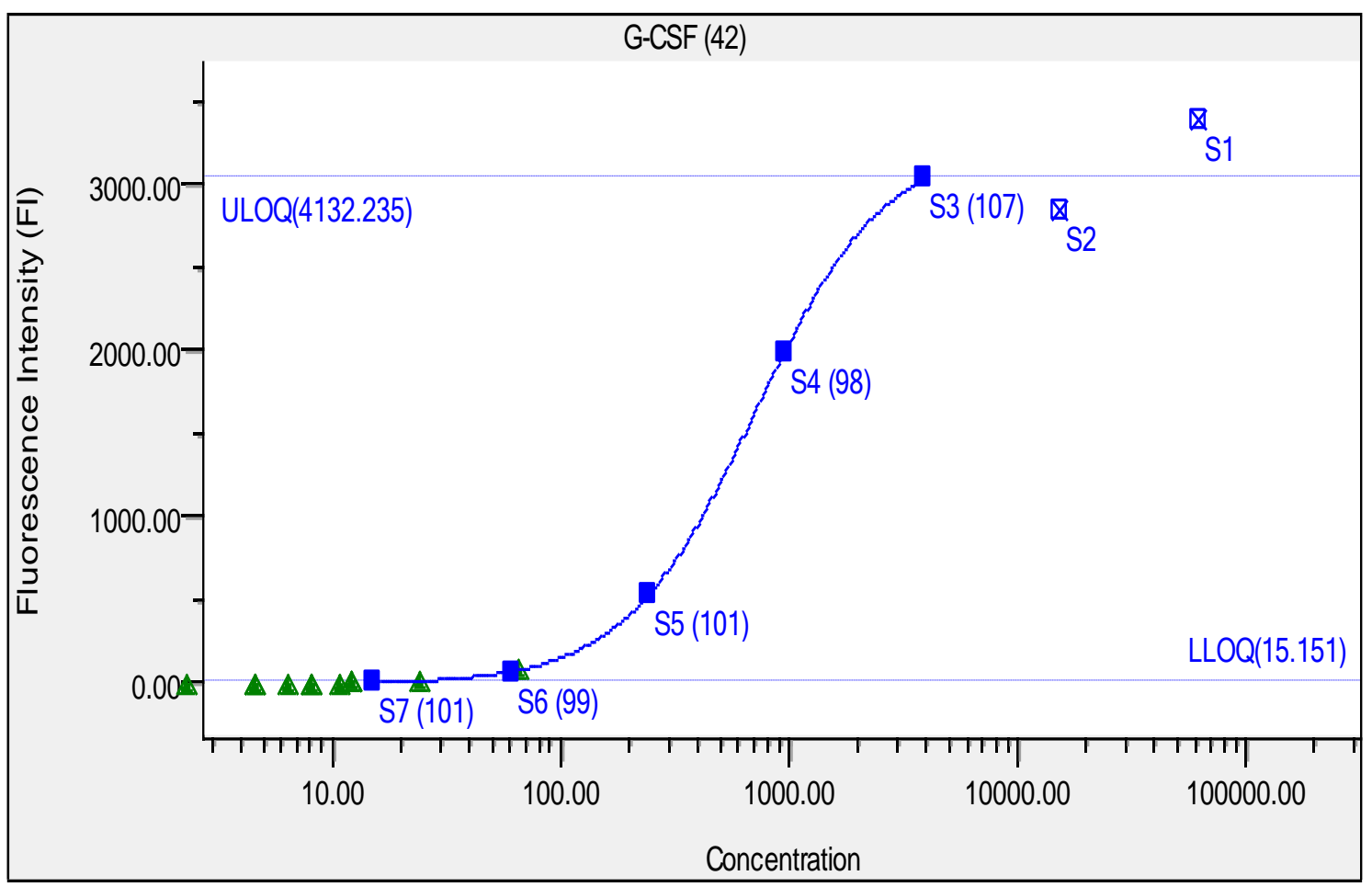

